\title{
Double Compressions of Atmospheric Depth by Geopotential Tendency, Vorticity, and Atmospheric Boundary Layer Affected Abrupt High Particulate Matter Concentrations at a Coastal City for a Yellow Dust Period in October
}

\author{
Hyo Choi ${ }^{1}$ and Mi Sook Lee ${ }^{2}$ \\ ${ }^{1}$ Department of Atmospheric and Environmental Sciences, Gangneung-Wonju National University, \\ Gangneung 210-702, Republic of Korea \\ ${ }^{2}$ Research Institute of East Sea Life Sciences, Gangneung-Wonju National University, Gangneung 210-702, Republic of Korea \\ Correspondence should be addressed to Hyo Choi; du8392@hanmail.net
}

Received 2 October 2013; Accepted 17 November 2013; Published 23 January 2014

Academic Editor: Chung-Ru Ho

Copyright (C) 2014 H. Choi and M. S. Lee. This is an open access article distributed under the Creative Commons Attribution License, which permits unrestricted use, distribution, and reproduction in any medium, provided the original work is properly cited.

\begin{abstract}
Using GRIMM-aerosol sampler, NOAA-HYSPLIT model, and 3D-WRF-3.3 model, the transportation of dusts from Gobi Desert toward Gangneung city, Korea was investigated from 09:00 LST October 27 to 04:00 LST October 28, 2003. Maximum PM10 (PM2.5, PM1) concentration was detected with $3.8(3.4,14.1)$ times higher magnitude than one in non-Yellow Dust period. The combination of dusts transported from the desert under westerly wind with particulate matters and gases from vehicles on the road of the city caused high PM concentrations near the ground surface at 09:00 LST and their maxima at 17:00 LST near sunset with further pollutants from heating boilers in the resident area. Positive geopotential tendency at the $500 \mathrm{hPa}$ level of the city $\left(\partial \Phi / \partial t ; \mathrm{m} \mathrm{day}^{-1}\right)$ corresponding to negative vorticity of $-4 \times 10^{-5} \mathrm{sec}^{-1}\left(-2.5 \times 10^{-5} \mathrm{sec}^{-1}\right)$ at 0900 LST (21:00 LST; at night) was $+83 \mathrm{~m} \mathrm{day}^{-1}\left(+30 \mathrm{~m} \mathrm{day}^{-1}\right)$ and it caused atmospheric depth between $500 \mathrm{hPa}$ level and the ground surface to be vertically expanded. However, its net reduction to $-53 \mathrm{~m} / 12 \mathrm{hrs}$ until 21:00 LST indicated synoptic-scale atmospheric layer to be vertical shrunken, resulting in the increase of PM concentrations at 17:00 LST. Simultaneously, much shallower microscale stable nocturnal surface inversion layer (NSIL) than daytime thermal internal boundary layer induced particulate matters to be merged inside the NSIL, resulting in maximum PM concentrations at 17:00 LST.
\end{abstract}

\section{Introduction}

In dry spring, air quality in the Korean eastern coastal region was greatly affected by huge amounts of dusts transported from the elevated ground of $1500 \mathrm{~m}$ above sea level of Taklamakan, Gobi, and Ordos Deserts and Loess plateau in NeiMongo in the northern China. In recent years, Yellow Dust Storm with various names of Yellow Sand Storm, Asian Dust Storm, and KOSA has been detected in even autumn and winter, showing a relatively lower concentration of particulate matters than one in spring [1-6]. The most concentrated region of Yellow Dust Storm has been known as northwest China, which included five provinces of Xinjiang, InnerMongolia (Nei-Mongo), Ningxi, Shanxi, and Gansu [7].
Zhang and Zhong [8] and Choi and Zhang [9] indicated that the regions of dust storm occurring more than 30 days per year coincide with those regions with both relative humidity of air less than $40 \%$ as the representation of the surface water content of the soil layer and surface wind speed greater than $10 \mathrm{~m} \mathrm{~s}^{-1}$. Tegen and Fung [10] explained that, among the total quantity of dust particulates generated from the deserts, its $30 \%$ is deposited near the source area and the $20 \%$ is redistributed on a local scale and the other half of them are expected to be subject to their long-range transports. The estimation of dust loading controlled by wind velocity has mainly been used, considering size distribution of soil particles and surface roughness in terms of friction velocity. Thus, the dust generated in Gobi Desert and Nei-Mongo in 
the northern China is to serve as one of the major particulate matter sources all across the Asia and Pacific and it makes a great contribution to low visibility and air quality in spring in northern Asian countries and even USA [11-15].

Kim et al. [16] showed that, during a Yellow Dust period in China, dusts generated from Gobi Desert were transported toward Seoul in the central region of Korea. Lee and Chung [17] also explained that a great amount of dusts from Gobi Desert were transported toward the Korean eastern mountainous coast, and the transported dusts from the desert usually included great amounts of particulate matters of not only coarse PM mode, but also fine one with various gases. Then, the transported dusts were combined with particulate matter and gases emitted from the downwind Korean cities, resulting in very high $\mathrm{PM}$ and gases concentrations with apparent temporal variations.

In the Yellow Dust researches, meteorological approach was usually focused on the beginning stage of the generation of dust storm and weather conditions for the formation of the dust storm, considering synoptic weather situationl [18]. When most of modelers perform the transport model, they have usually treated atmospheric boundary layer to be constant, even actually not constant, assuming $1.5 \mathrm{~km}$ or $2 \mathrm{~km}$ height above the ground surface. However, Choi and Zhang [9] insisted that the transportation of dusts from Gobi Desert toward the far downwind area like Korean peninsula is initially greatly affected by synoptic- and mesoscale wind fields. Choi and Speer [19], Choi and Choi [20], and Choi et al. [21, 22] further insisted the effects of variability of atmospheric boundary layer depth during the day and night on high concentrations of locally emitted particulate matters combined with dusts from the north China. Owing to no much considering those subjects in the transport model of dusts, the occurrence of abrupt high concentrations of dust particles in the downwind local area have been still obscured so far.

In recent, Choi [23] showed the trapping effect of a calm zone by lee side-internal gravity waves and cyclonic winds on sudden high concentrations of particulate matters combined with the Yellow Dusts from Gobi Desert in the Korean eastern coast. Differently, Uzan and Alpert [24] explained that the highest air pollution events such as $\mathrm{SO}_{2}$ and $\mathrm{NO}_{x}$ concentrations (not particulate matter) from Israel's largest coal-fired power plant occurred during summer at 12:00 15:00 h through the average coincident drop of the boundary layer height down to $450 \mathrm{~m}$ above the ground. Even though they did not consider the transportation of gases from other city into the research area, the research result indicated that pollutant concentration should be directly affected by the depth of atmospheric boundary layer.

Precisely understanding the evolution of atmospheric boundary layer is also one of the most important aspects for the horizontal transportation of the dust and its sudden high concentration in the far downwind area like Korea, considering synoptic and mesoscale motions of atmosphere. Choi and Lee [25] made primary research on abrupt high PM concentration during the dust period in October, 2003, considering shrunken atmospheric boundary layer, but they did not explain dynamically any relation of synoptic-scale atmospheric shrunken process with diurnal variations of atmospheric boundary layer. The purpose of this study is to explain the effects of double compression of not only synoptic-scale atmospheric layer varied by geopotential tendency and vorticity at $500 \mathrm{hPa}$ level, but also microscale atmospheric boundary layer on the occurrence of abrupt high particulate matter concentration in the mountainous coastal region of Korea, during a Fall Yellow Dust period.

\section{Study Area}

Figure 1 indicates Northeastern Asia including the study area near Gangneung city $\left(37^{\circ} 45^{\prime} \mathrm{N}, 128^{\circ} 54^{\prime} \mathrm{E}\right.$; $20 \mathrm{~m}$ height above Mean Sea Level) in the Korean eastern coastal region. Gangneung city consists of high mountains in the west of the city, coastal basin in its center, and sea in its east and its population is about 230,000 with no special industries.

The city has the characteristics of continental and marine climates due to its location between mountains and sea. Particularly, fall season is short, and weather in winter is mild due to the passage of the East Korea Warm Current (EKWC; branch currents of Kuroshio Warm Current) bounding for north along the eastern coast of Korean peninsula. As it is a clean coastal city without special industries, air pollution sources are mainly vehicles of about 50,000 on the road, flying dusts from the road, and heating boilers in the resident area and the city has typical urban characteristics. In Spring, air quality is greatly affected by the dust particles transported from the northern China, especially Gobi Desert and Neimongo (Inner Mongolia) such as arid area in China and Mongolia.

\section{Aerosol Measurement and Numerical Model}

3.1. Measurement of Aerosol. GRIMM-1107 aerosol sampler was equipped at Gangwon Regional Meteorological Administration (20 m height above Mean Sea Level) in the downtown of Gangneung city adjacent to the East Sea of Korea on October 26 29, 2003, under air quality at Gangneung city to be greatly affected by dusts transported from Gobi Desert. GRIMM-1107 aerosol sampler is characterized as a portable particle analyzer measuring particulates of $0.3 \sim 20 \mu \mathrm{m}$ by way of laser-light scattering, with a monitor on particulate matter concentrations $\left(\mathrm{PM}-\mathrm{PM}_{10}, \mathrm{PM}_{2.5}\right.$, and $\left.\mathrm{PM}_{1}\right)$ to offer dual technology consisting of both optical and gravimetrical analysis.

After air of various particle sizes passes through a flat laser beam produced by a precisely focused laser and several collimator lenses, the scattered light is detected by a 15channel, pulse-height analyzer for size classification at every 5 seconds and then the counts from each size classification are directly converted to mass by an established equation to be specifically designed for $\mathrm{PM}_{10}, \mathrm{PM}_{2.5}$, and $\mathrm{PM}_{1}$ ambient air analysis [22]. $\mathrm{PM}_{10}, \mathrm{PM}_{2.5}$, and $\mathrm{PM}_{1}$ are presented on the monitor and stored in a data log with every 10-minute averaged PM concentrations and total counts of different sizes. 


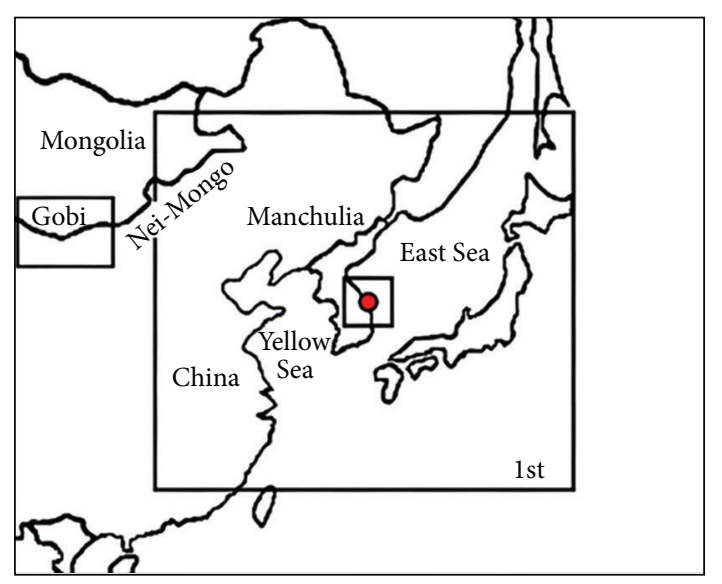

FIgURE 1: Topography of the northeastern Asia including Gangneung city $\left(37^{\circ} 45^{\prime} \mathrm{N}, 128^{\circ} 54^{\prime} \mathrm{E}\right)$ with the establishment of a GRIMM aerosol sampler. Large and small squares in the center indicate the first domain with a $27 \mathrm{~km}$ grid interval on $91 \times 91$ horizontal grids and the third domain with a $3 \mathrm{~km}$ by three-nesting techniques in the WRF model simulation. A square in the left and a circle in the center denote Gobi Desert and Gangneung city equipped with an aerosol sampler, respectively.

3.2. Numerical Model and Input Data. For the numerical simulation of the generation of meteorological phenomena, Weather Research \& Forecasting Model (WRF) version 3.3a three-dimensional, nonhydrostatical grid point model with a terrain following coordinate system-was adopted on the route of dust transportation from China to Gangneung city in the eastern coast of Korea from 00:00 UTC (Local Standard Time $(\mathrm{LST})=9 \mathrm{~h}+$ UTC (Coordinated Universal Time); 09:00 LST in Korea), October 27 through 00:00 UTC, October 29, 2003. In the numerical simulation, one way-triple nesting process from a coarse-mesh domain to a fine-mesh domain was performed using a horizontal grid spacing of $27 \mathrm{~km}$ covering a $91 \times 91$ grid square in the largest domain. The second and third domains also consist of the same grid square of $91 \times 91$ with $9 \mathrm{~km}$ and $3 \mathrm{~km}$ horizontal grid intervals, respectively [20].

National Centers for Environmental Prediction/National Center for Atmospheric Research (NCEP/NCAR) reanalysisFinal Analyses $(\mathrm{FNL}) 1.0^{\circ} \times 1.0^{\circ}$ resolution data were used as meteorological input data of WRF model and the data were vertically interpolated onto 36 levels with sequentially larger intervals increasing with height from the surface to the upper boundary level of $100 \mathrm{hPa}$ [20]. Among various parameterization schemes of WRF model, WSM 6 scheme was used for microphysical processes for the heat and moist budgets in the atmospheric boundary layer, and the YSU PBL scheme for the planetary boundary layer. Furthermore, the Kain-Fritsch (new Eta) for cumulus parameterization, the five thermal diffusion model for land surface, and the RRTM long wave radiation scheme and Dudhia short wave radiation schemes were also used. Input terrain data with a horizontal resolution of $1^{\circ}$ (about $110 \mathrm{~km}$ ) were used for the first-largest domain, and $1 \mathrm{~km}$ horizontal resolution data were for the second and third domains [23].
Horizontal wind, air temperature, and $500 \mathrm{hPa}$ height change for 24 hours (i.e., geopotential tendency $(\partial \Phi / \partial t)$; $\mathrm{m} /$ day), relative vorticity $\left(\times 10^{-1} \mathrm{sec}^{-1}\right)$ were evaluated in northeastern Asia and further both horizontal and vertical profiles of wind, air temperature, potential temperature, and potential vorticity for investigating the development of atmospheric boundary layer near Gangneung city of the Korea, sequentially in the three-mesh domains in the WRF model. For the verification of numerical results of the meteorological elements, wind, air temperature, and relative humidity by Gangwon Regional Meteorological Administration were used.

\section{Result and Discussion}

4.1. Aerosol Concentration during a Non-Yellow Sand Period. Figure 2 indicates hourly distribution of $\mathrm{PM}_{1}, \mathrm{PM}_{2.5}$, and $\mathrm{PM}_{10}$ concentrations at Gangneung city with no special industry in the eastern mountainous coast of Korea from 00:00 LST (09:00 LST), October 26 to 18:00 LST, October 29, 2003. Its main air pollution sources to affect local PM concentrations are vehicles on the road and heating boilers in the resident area. As air temperature of Gangneung city is in the range of $10 \sim 15^{\circ} \mathrm{C}$ for daytime hours in the late October and is lower than about $10^{\circ} \mathrm{C}$ at night, heating boilers in the resident area are put into operation for a few hours around sunset and sunrise. This operation can partially affect the increase of particulate matter and gases such as $\mathrm{CO}$ and $\mathrm{NO}_{x}$ concentrations.

A low pressure system of $999 \mathrm{hPa}$ was located in the northern border of Mongolia and a high pressure system of $1021 \mathrm{hPa}$ in the East Sea of Korea on weather map supplied by Korea Meteorological Administration (KMA) at 09:00 LST, October 26 (Figure 3(a)). The pressure patterns produced northwesterly wind near Gobi Desert and the wind could blow dusts generated by Gobi Desert toward Manchuria in the north-eastern China. Under this situation, the dusts could not be transported toward Gangneung city in the eastern coast of the Korean peninsula (triangle).

As weather map or wind fields generated by a meteorological numerical model just show flow patterns of air particles at a certain height and at a given time of a special day. Thus, if we want to know the flow patterns of air particles continuously at different heights, we use many numbers of weather maps or simulated wind fields by a model at every 3 or 6 hours intervals for several days. On the other hand, particle trajectory using NOAA-HYSPIT model, which consists of meteorological model for wind field and Lagrangian random walk model on particle diffusion and dispersion, can supply the moving paths of air particles and their positions with different flowing heights at every 6 hours for several days, continuously. Thus, the position of air particle at a certain time on the moving trajectory of air for several days should be exactly the same as flow pattern of air at a given time weather map of a special day or wind field by a numerical model at a certain height. However, it is very difficult to chase the track of air particle on the weather map. Thus, we commonly use backward trajectory of air 


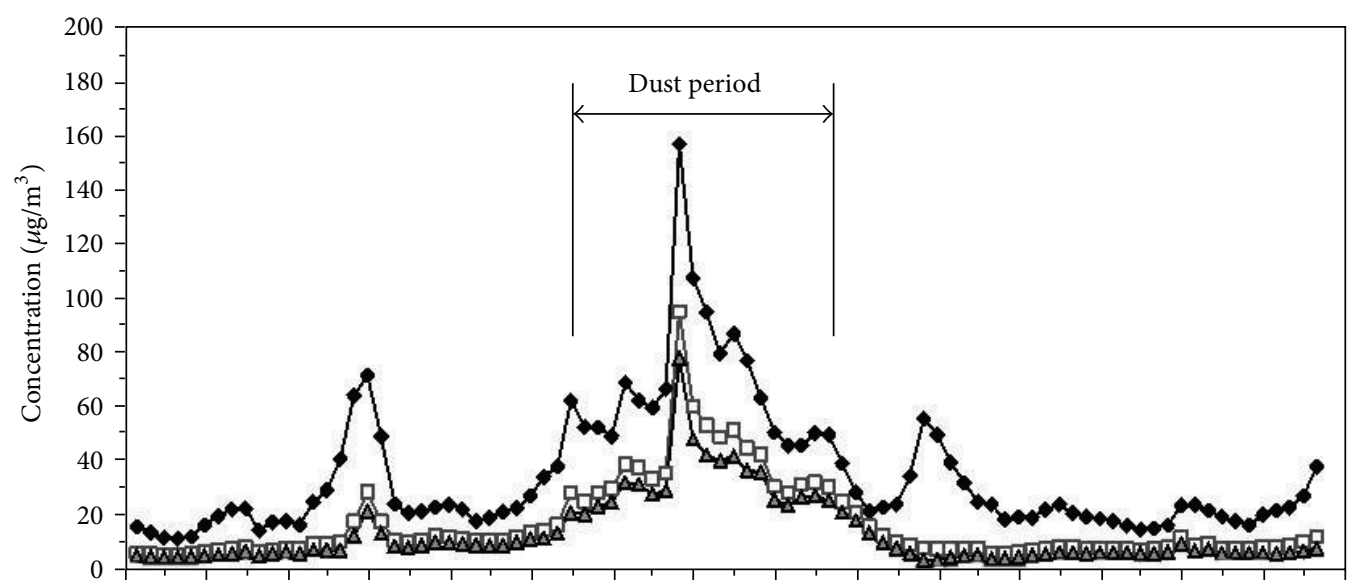

$\begin{array}{lllllllllllllllll}10-26 & 10-26 & 10-26 & 10-26 & 10-27 & 10-27 & 10-27 & 10-27 & 10-28 & 10-28 & 10-28 & 10-28 & 10-29 & 10-29 & 10-29 & 10-29\end{array}$ $\begin{array}{llllllllllllllll}00: 00 & 06: 00 & 12: 00 & 18: 00 & 00: 00 & 06: 00 & 12: 00 & 18: 00 & 00: 00 & 06: 00 & 12: 00 & 18: 00 & 00: 00 & 06: 00 & 12: 00 & 18: 00\end{array}$

Time

$$
\begin{aligned}
& \smile \mathrm{PM}_{10} \\
& -\square \mathrm{PM}_{2.5} \\
& \triangle \mathrm{PM}_{1.0}
\end{aligned}
$$

FIgURE 2: Hourly distributions of $\mathrm{PM}_{10}, \mathrm{PM}_{2.5}$, and $\mathrm{PM}_{1}$ concentrations at Gangwon Meteorological Administration in the downtown of Gangneung city, Korea from October 26 29, 2003.

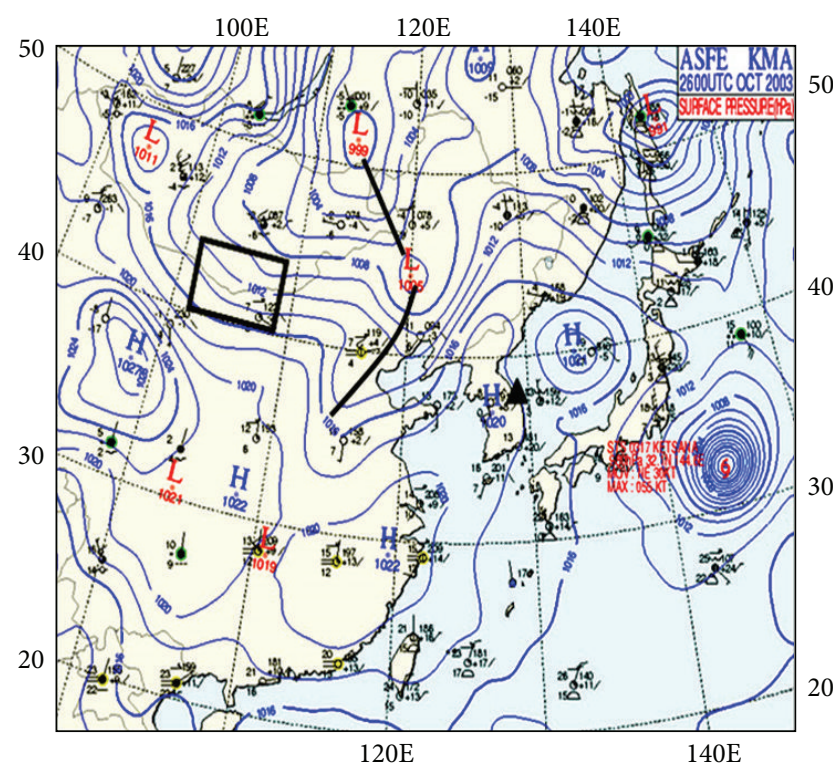

(a)

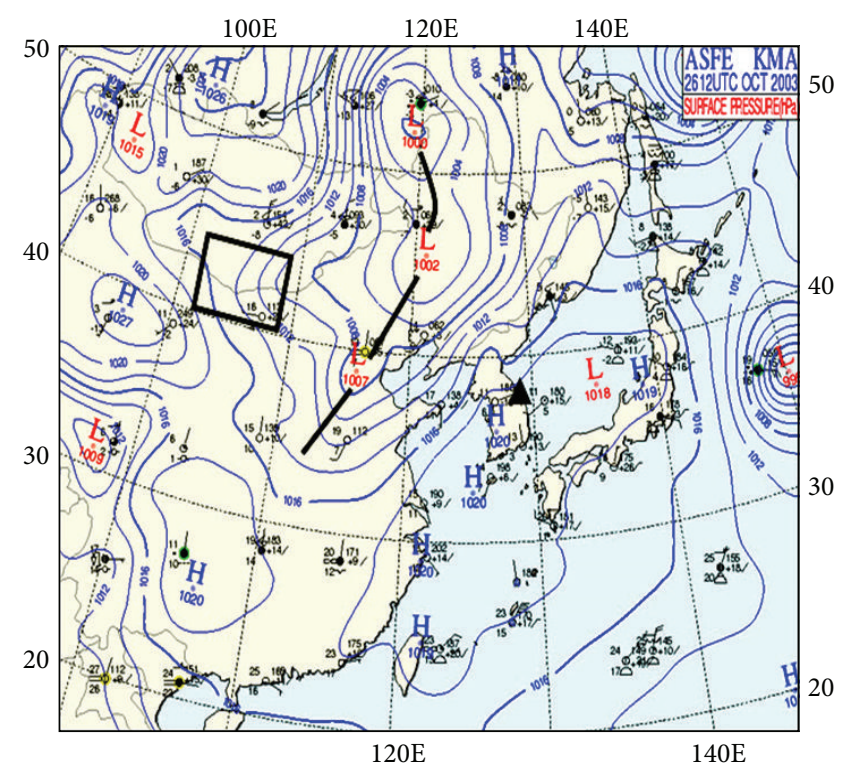

(b)

FiguRE 3: Surface weather maps at (a) 09:00 LST (00:00 UTC), October 26, 2003, and (b) 21:00 LST (12:00 UTC), supplied by KMA [26]. Square and thick line in (a) and (b) indicate Gobi Desert extending from the southern Mongolia to the northern China and cold front. Northwesterly wind in the left of cold front and southwesterly wind in the right of the front produced a main stream of dust particles originated from Gobi Desert toward Liaoning province in the northeastern China, which is far away from Gangneung city.

particle by NOAA-HYSPLIT model, which focuses only main stream of the majority of particles, not showing diffusion and dispersion of whole particles. Choi and Speer [19] described that the trajectories of whole particles in the wide area of different height such as in Seoul city and Korean eastern coast could be shown using Lagrangian Random Walk Model combined with meteorological model, but if we want to know the main stream of particles, not considering whole particles, HYSPLIT model is strongly recommended. In general, to investigate flow pattern of air in the wide area, it is necessary to review weather maps and horizontal wind fields generated by a meteorological numerical model.

For depicting backward trajectories of dust particles with time, NOAA HYSPLIT model (hybrid single particle 


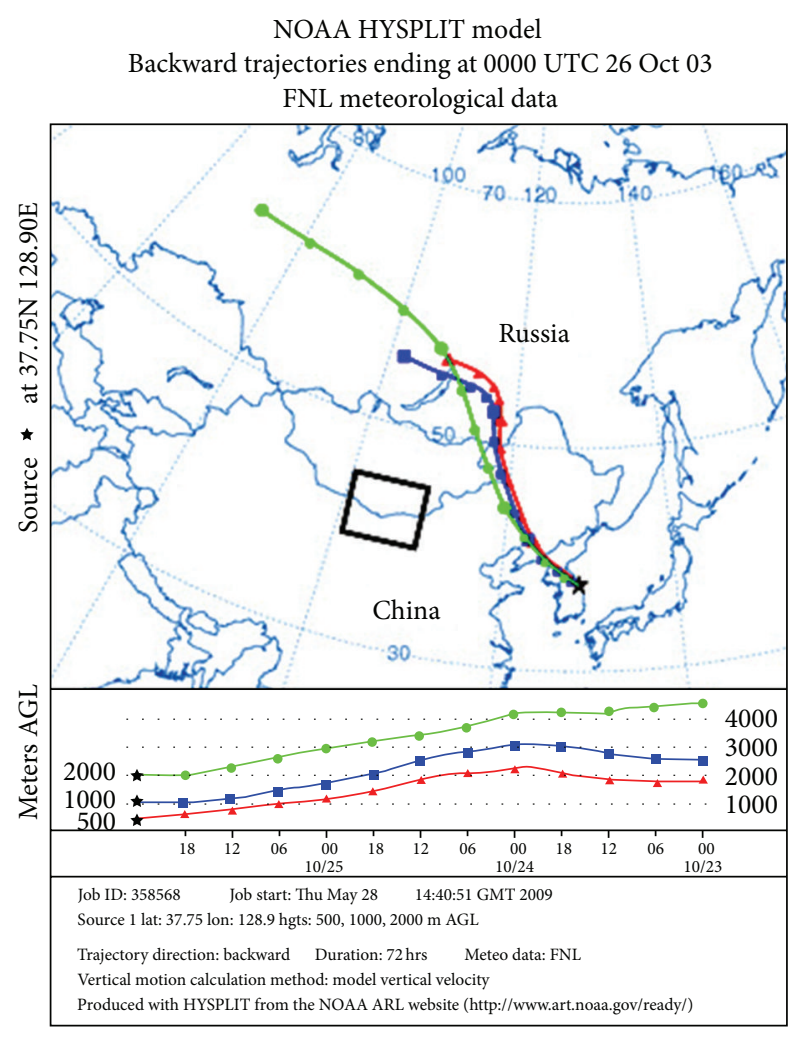

(a)
NOAA HYSPLIT model

Backward trajectories ending at 1200 UTC 26 Oct 03

FNL meteorological data

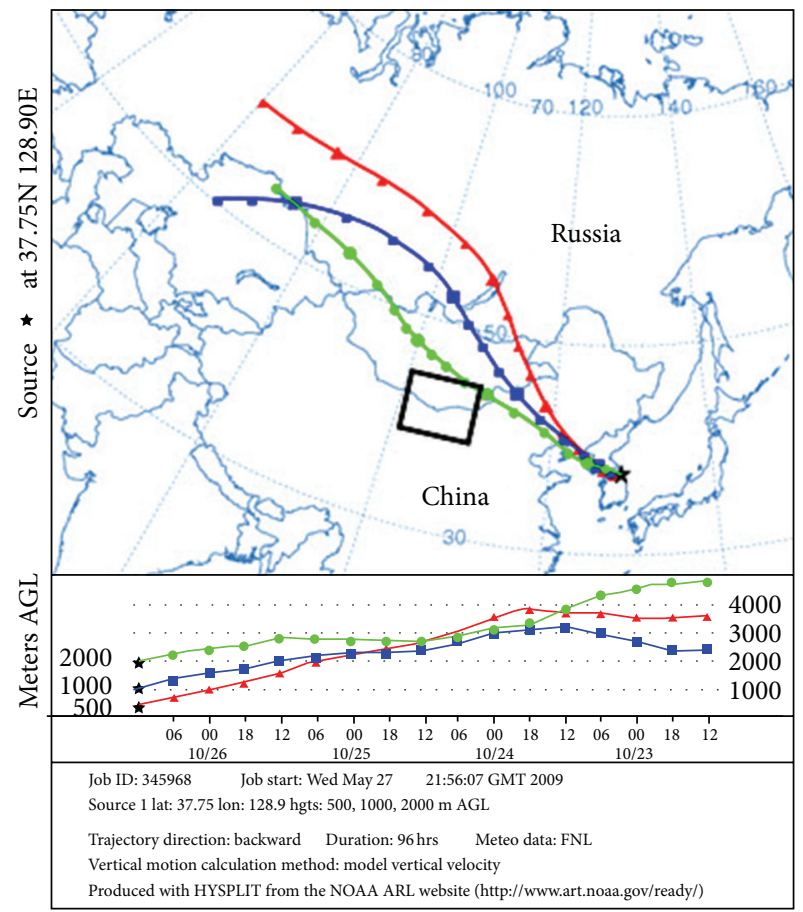

(b)

Figure 4: Backward trajectories of air masses at $2000 \mathrm{~m}, 1000 \mathrm{~m}$, and $500 \mathrm{~m}$ heights by NOAA HYSPLIT model ending at (a) 09:00 LST (00:00 UTC), October 26, 2003 and (b) 21:00 LST (12:00 UTC). Clean air masses from above $2 \mathrm{~km}$ height of the north-eastern Mongolia flew toward Gangneung city at each level in (a) and ones from above $3 \mathrm{~km}$ height outside Gobi Desert (Nei-Mongo in the northeastern China) reached $1000 \mathrm{~m}$ and $2000 \mathrm{~m}$ heights of the city, without dust transportation to the city in (b). As weather map or wind fields generated by a meteorological numerical model just show flow patterns of air at a certain height and at a given time of a special day, but particle trajectory using NOAA-HYSPIT model supplies the moving path (main stream) of majority of air particle and its position at every 6 hours for several days, continuously.

Lagrangian integrated trajectory) from the Air Resources Laboratory (ARL) using FNL meteorological data was adopted and the heights of dust particle trajectories were set up at $2000 \mathrm{~m}, 1000 \mathrm{~m}$, and $500 \mathrm{~m}$, respectively (Figure 4). This model showed very detailed information on temporal transportation routes of dust particles for several days and their flowing height and spreading area. Weather map or wind fields generated by a meteorological model just show flow patterns of air at a given time, but particle trajectory using NOAA HYSPIT model supplies the moving path of particle and its position at every 6 hours for several days, continuously. Thus, this moving trajectory for several days is different from a given time weather map or wind field given by a numerical model. Unfortunately some environmental scientists misunderstand their differences. Thus, back trajectories with a time step of 6 hours over a period of 72 or 96 hours using the HYSPLIT model were depicted at $500 \mathrm{~m}, 1000 \mathrm{~m}$, and $2000 \mathrm{~m}$ above ground level in order to detect possible links between diurnal variation of PM concentrations and pathway of dust particles transported from Gobi Desert and Nei-Mongo (Inner Mongo) in the northern China toward a Korean eastern coastal city.
At 09:00 LST (00:00 UTC), October 26, clean air masses originated from over $2 \mathrm{~km}$ height in the north-eastern Mongolia far away from Gobi Desert reached Gangneung city at $500 \mathrm{~m}, 1000 \mathrm{~m}$, and $2000 \mathrm{~m}$ heights and the city was under no influence of dusts in Gobi Desert (Figure 4(a)). At 21:00 LST, the previous low pressure system moved toward the east and stretched toward the south-eastern China with pressure centers of $1000 \mathrm{hPa}, 1002 \mathrm{hPa}$, and $1007 \mathrm{hPa}$, respectively (Figure 3(b)). A high pressure system of $1026 \mathrm{hPa}$ was located in the northern Mongolia, but Gobi Desert was still under the influence of the low pressure system.

The pressure patterns over Mongolia, China, and Korea caused northwesterly wind near Gobi Desert in the left of cold front and southwesterly in the right. Dusts driven by those winds should pass by Manchuria of the north-eastern China in the north of the Korean peninsula, resulting in no influence of dust transportation from China to Gangneung city of Korea (triangle). Figure 4(b) showed that, on backward trajectory, relatively clean air particles from above $3 \mathrm{~km}$ height of Gobi Desert reached $1000 \mathrm{~m}$ and $200 \mathrm{~m}$ heights of the Korean city at 21:00 LST, October 26, but it was very difficult to expect dust transportation from Gobi Desert to 


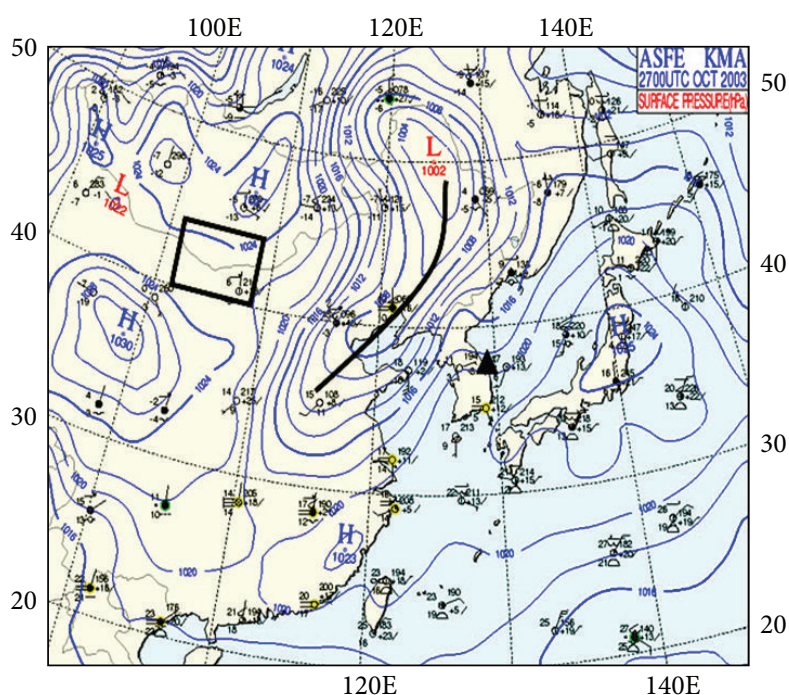

(a)

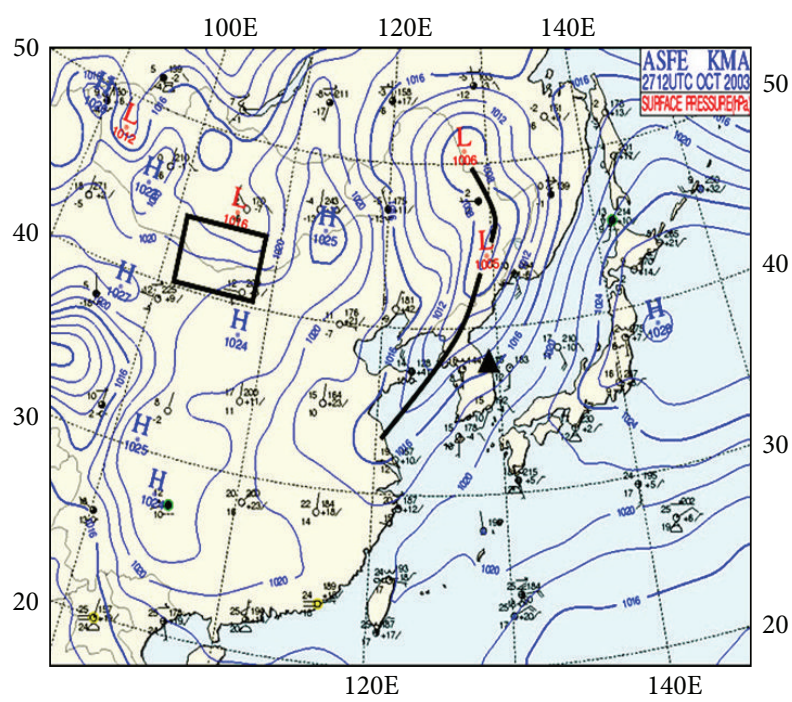

(c)

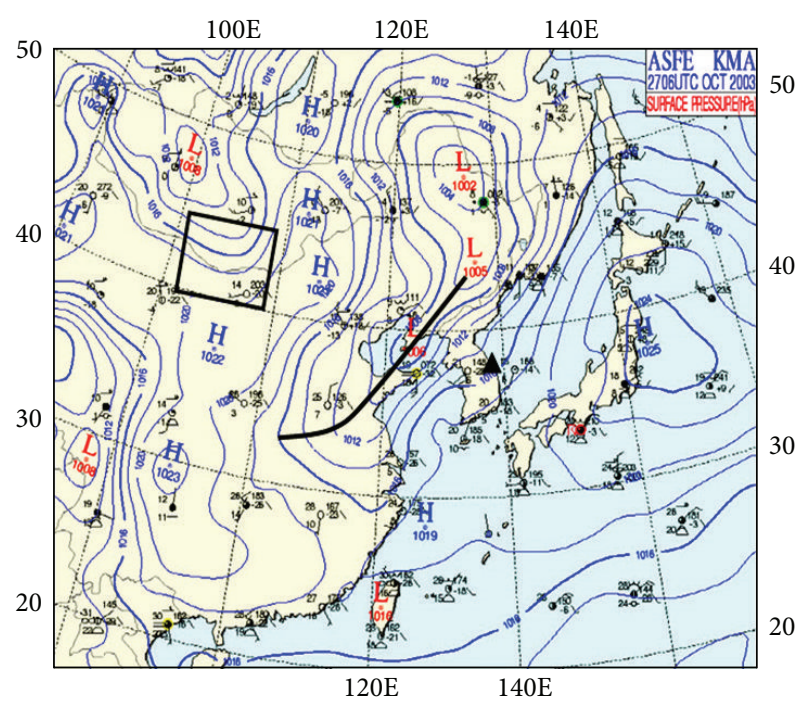

(b)

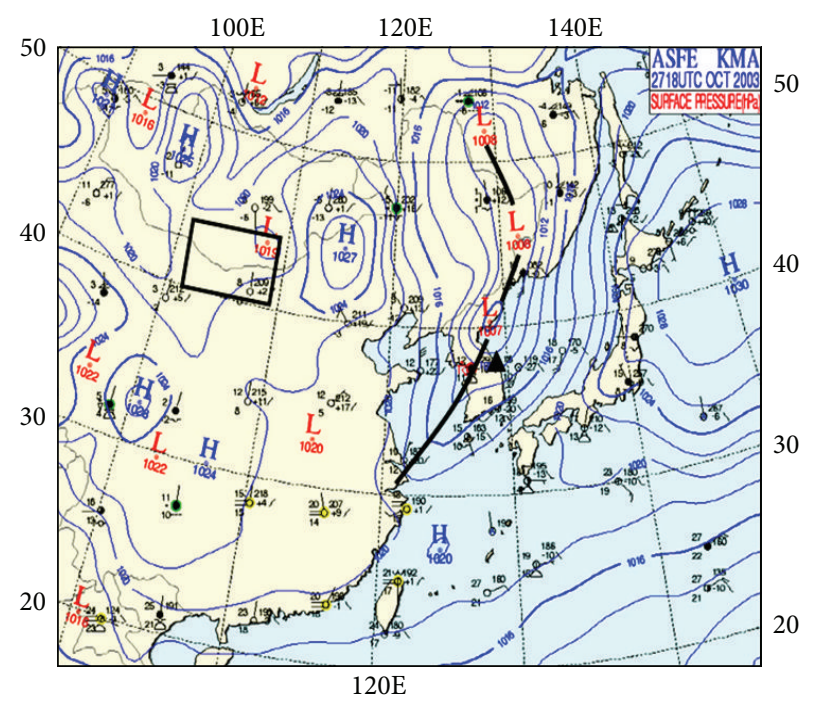

(d)

Figure 5: As shown in Figure 3, except for (a) 09:00 LST (00:00 UTC), (b) 15:00 LST (06:00 UTC), (c) 21:00 LST (12:00 UTC), October 27, 2003, and (d) 03:00 LST (18:00 UTC), October 28. Dust particles originated from Gobi Desert move toward eastern Nei-Mongo, Manchuria, and northern Korea with their flowing southwestward in the left of cold front and northeastward in the right of the front, as the front moves toward the Korean peninsula, sequentially with time.

the city. Nontransportation of dust from Gobi Desert and the northern China toward the city continued to be until 08:00 LST, October 27 in Figure 2.

In Figure 2, on October 26, especially before 09:00 LST October 27, under no intrusion of dust from Gobi Desert or Nei-Mongo (Inner Mongolia) in the northern China toward the city (non-Yellow Dust period), $\mathrm{PM}_{1}, \mathrm{PM}_{2.5}$, and $\mathrm{PM}_{10}$ concentrations near the ground surface of Gangneung city were generally very low, more or less than $20 \mu \mathrm{g} \mathrm{m}^{-3}$, $10 \mu \mathrm{g} \mathrm{m}^{-3}$, and $5 \mu \mathrm{g} \mathrm{m}^{-3}$, except for $\mathrm{PM}_{10}$ of $69.87 \mu \mathrm{g} \mathrm{m}^{-3}$ at 18:00 LST, October 26, respectively. High $\mathrm{PM}_{10}, \mathrm{PM}_{2.5}$, and $\mathrm{PM}_{1}$ concentrations were detected at 09:00 LST at the beginning time of office and 18:00 LST at the ending time of office hour, due to high density of traffic vehicles on the road at both times. Particularly maximum PM concentrations at 18:00 LST rather than 09:00 LST were shown due to additionally nighttime more operating of heating boilers in the resident area of the city, shortly after sunset. This hourly PM concentration showed a typical urban type-high PM concentrations around 09:00 LST in the morning and 18:00 LST near the sunset.

4.2. Aerosol Concentration during a Yellow Sand Event Period. During the intrusion of dust transported from Gobi Desert of the northern China toward the city from 09:00 LST October 27 04:00 LST, October 28 (Yellow Dust period), 


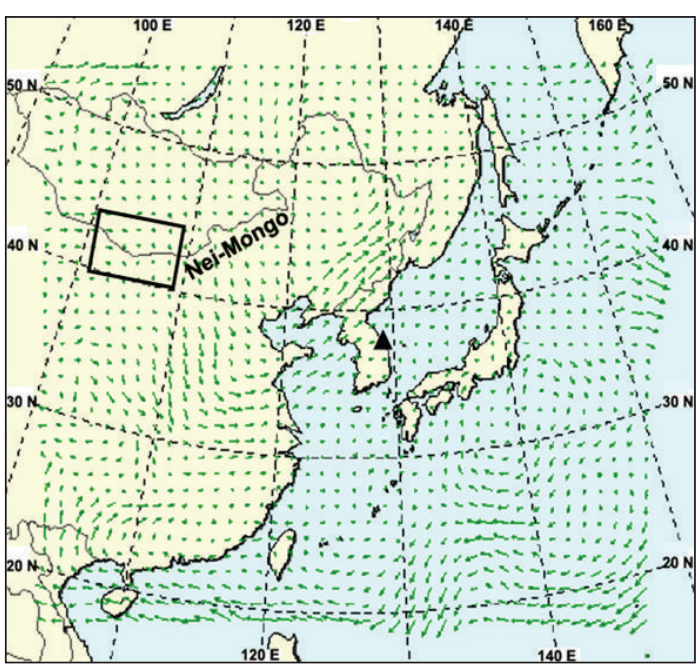

(a)

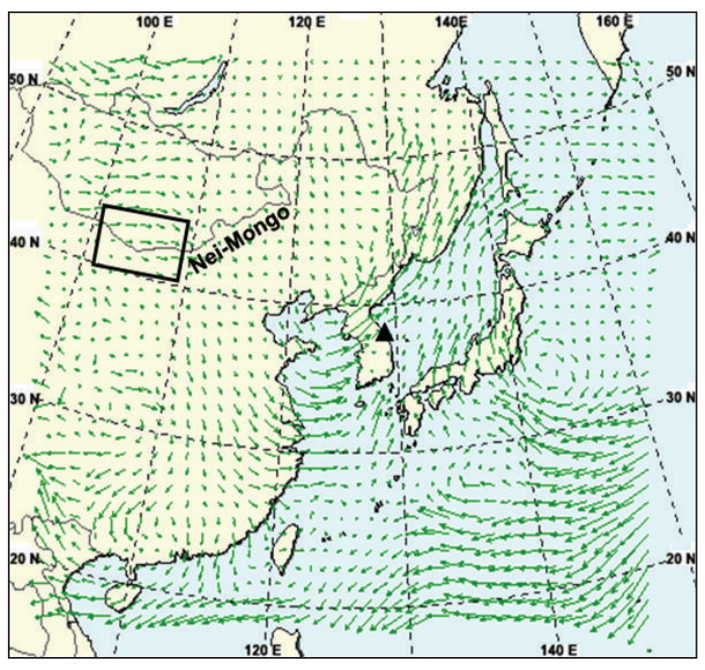

(c)

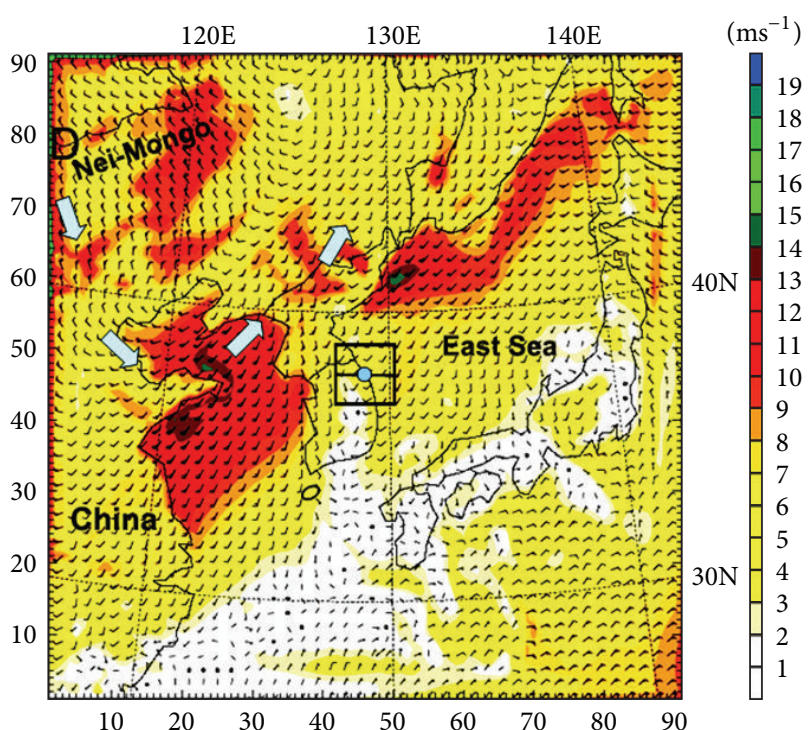

(b)

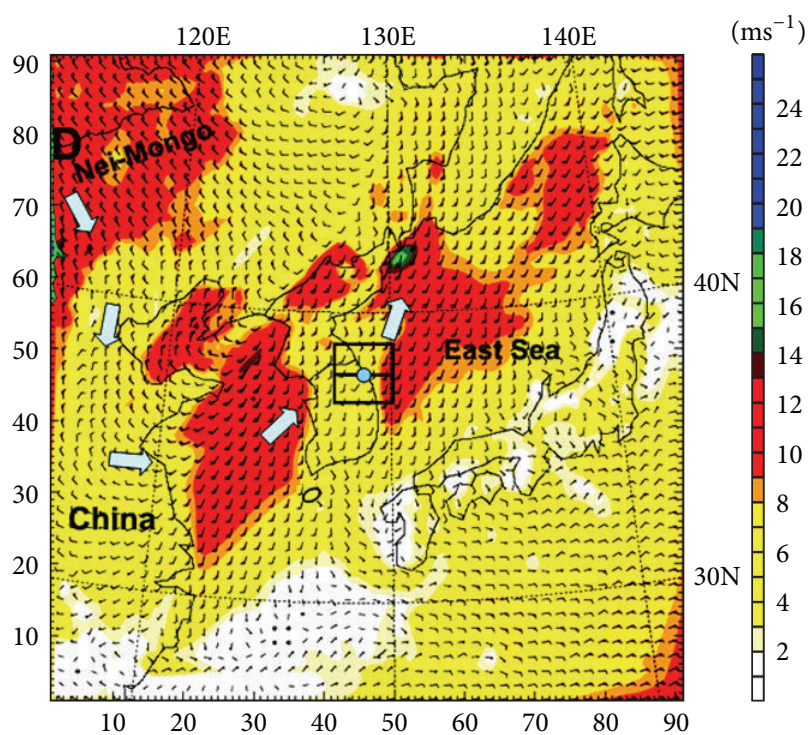

(d)

Figure 6: (a) Moisture flux (m/s) at $850 \mathrm{hPa}$ level (about $1.5 \mathrm{~km}$ height) supplied by KMA [26] and (b) surface wind (m/s) simulated by WRF model at 09:00 LST, October 27, 2003, and (c) and (d) are at 17:00LST (a maximum PM concentration), respectively. Small square and triangle in (a) and (c) denote Gobi Desert and Gangneung city (Korea). Small square in (b) and (d) denotes the vicinity of Gangneung (the 3rd domain of WRF model) at 09:00 LST, October 27, 2003 and 17:00 LST (occurrence time of maximum PM concentration). D and big arrow denote the eastern part of Gobi Desert in the northwest of Nei-Mongo and a dust transportation route. In (a), (b), (c), and (d), dust particles originated from Gobi Desert moved toward Nei-Mongo under westerly wind at both the surface and $1.5 \mathrm{~km}$ height and then, followed northerly and northwesterly toward the Chinese eastern coast and the Yellow Sea, further moving toward the northern Korea and Gangneung city.

$\mathrm{PM}_{10}$ concentration was in the range of $48.20 \sim 154.57 \mu \mathrm{g} \mathrm{m}^{-3}$ and its maximum concentration was 3.8 times higher than the maximum concentration of nondust period.

Similarly, $\mathrm{PM}_{2.5}\left(\mathrm{PM}_{1}\right)$ concentration was in the range of $26.92 \sim 93.19 \mu \mathrm{g} \mathrm{m}^{-3}\left(19.63 \sim 76.05 \mu \mathrm{g} \mathrm{m}^{-3}\right)$ with a maximum concentration of 3.4 (14.1) times higher than one of nondust period and their hourly variations of PM concentrations were similar each other (Figure 2). High $\mathrm{PM}_{10}\left(\mathrm{PM}_{2.5}\right.$ and $\left.\mathrm{PM}_{1}\right)$ concentration was detected with $60.59 \mathrm{\mu g} \mathrm{m}^{-3}\left(26.92 \mu \mathrm{g} \mathrm{m}^{-3}\right.$,
19.63 $\mu \mathrm{g} \mathrm{m}^{-3}$ ) at 09:00 LST, October 27 (the beginning time of office hour), when a high traffic density on the road took place. PM concentration after 09:00 LST had a rapid increasing trend until 17:00 LST.

As shown in surface weather maps of Figure 5(a), one can expect that dusts generated in Gobi Desert in the northern China could be transported following isobaric lines of a high pressure, showing arrow movement of air masses in the figure. As shown in surface winds simulated by WRF-3.3 
NOAA HYSPLIT model

Backward trajectories ending at 0000 UTC 27 Oct 03

FNL meteorological data

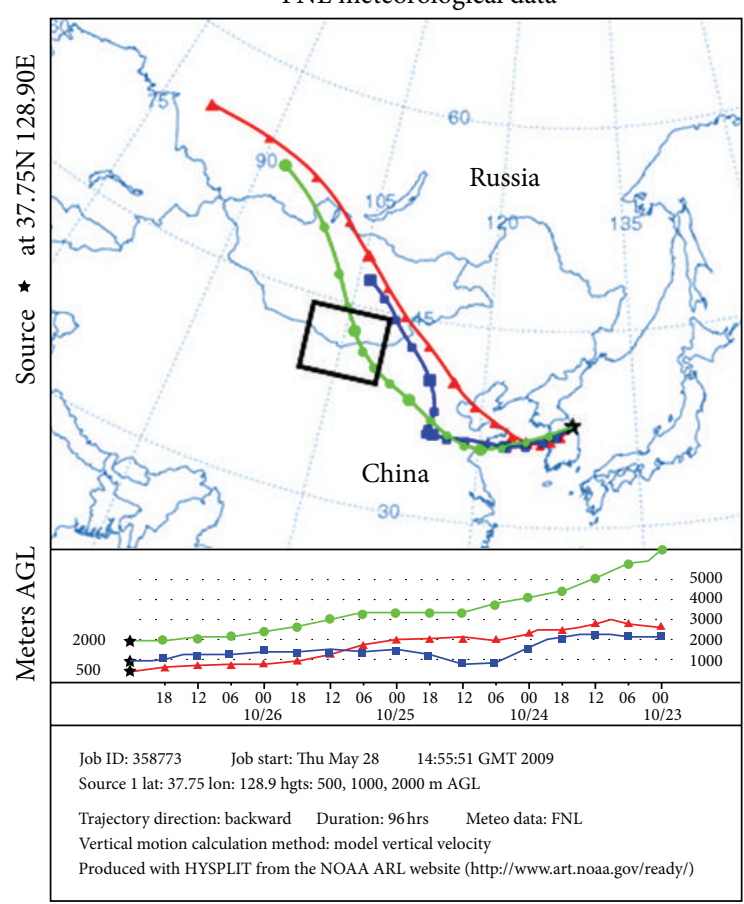

(a)

NOAA HYSPLIT mode

Backward trajectories ending at 1800 UTC 27 Oct 03

FNL meteorological data

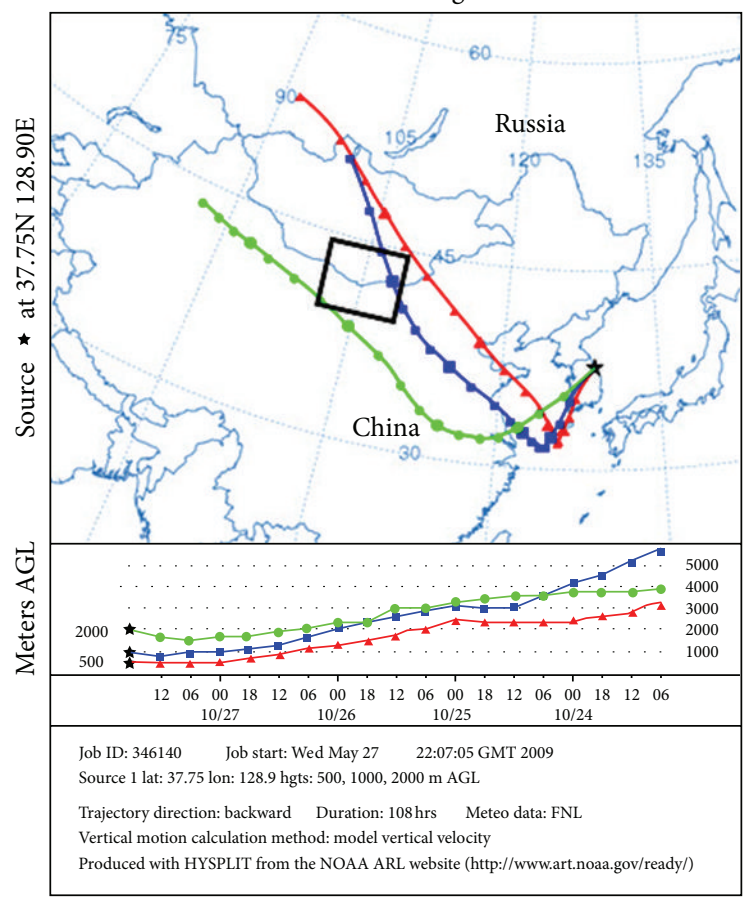

(c)
NOAA HYSPLIT model

Backward trajectories ending at 0800 UTC 27 Oct 03

CDC1 meteorological data

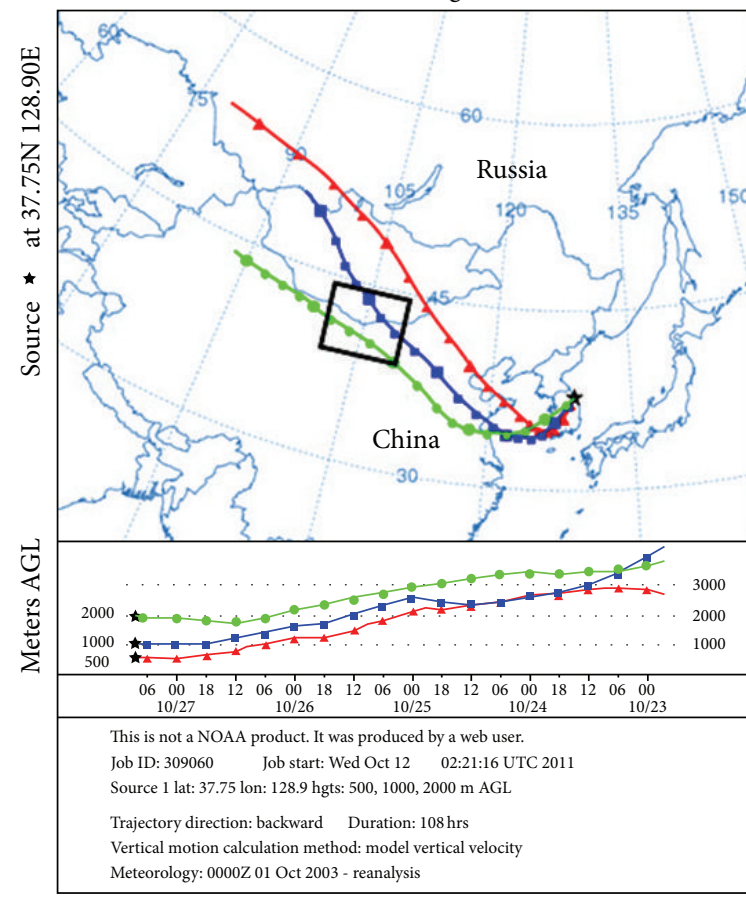

(b)

NOAA HYSPLIT model

Backward trajectories ending at 0000 UTC 28 Oct 03

FNL meteorological data

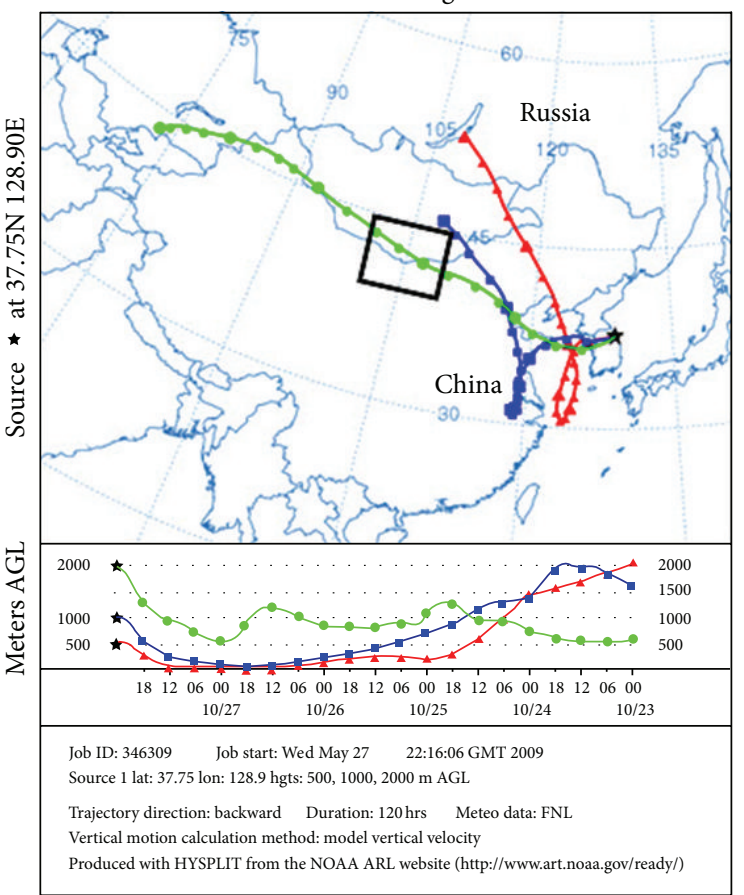

(d)

FIGURE 7: Backward trajectories of air masses by NOAA HYSPLIT model ending at (a) 09:00 LST (00:00 UTC), October 27, 2003, (b) 17:00 LST (08:00 UTC; a maximum PM concentration), (c) 03:00 LST (18:00 UTC), October 28, and (d) 09:00 LST (00:00 UTC), respectively. 


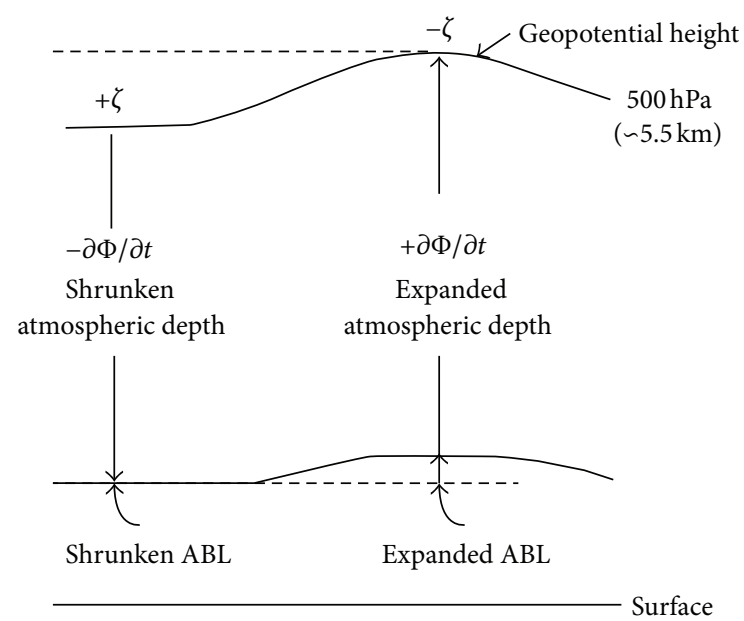

FIGURE 8: Schematic profile of geopotential height change with time (geopotential tendency $(\partial \Phi / \partial t) ; \mathrm{m} \mathrm{day}^{-1}$ ) at $500 \mathrm{hPa}$ level (approximately $5.5 \mathrm{~km}$ height) and atmospheric boundary layer (ABL), modified from Choi et al. [28]. Negative geopotential tendency $(\partial \Phi / \partial t)$ means the decrease of geopotential height for 24 hours (i.e., shrunken atmospheric layer) and vice versa. Positive vorticity $(+\zeta=\partial v / \partial x-\partial u / \partial y)$ at the $500 \mathrm{hPa}$ level, which implies the downward motion of air toward the ground corresponds to negative geopotential tendency area and vice versa.

model, strong northerly surface wind in the north of China and southwesterly in the south prevailed (Figures 6(a) and 6(c)). In general, dusts generated from dried soil of the desert ground could be uplift to about $3 \mathrm{~km}$ height over the ground surface due to strong surface wind and daytime thermal convection [7], and then they moved eastward below the lower level than $3 \mathrm{~km}$ height.

Figure 6(a) at 09:00 LST, October 27, and Figure 6(c) at 17:00 LST of the occurrence time of a maximum PM concentration indicate transportation routes of moisture fluxes at about $1.5 \mathrm{~km}$ height ( $850 \mathrm{hPa}$ level) in Mongolia, China, Korea, and Japan, which well show the movement of air parcel with water vapor. From these figures, it is very easy to find the transportation route of dust particles combining with air, water vapor, and dust. In Figures 6(a), 6(b), 6(c), and 6(d), dust particles originated from Gobi Desert moved toward Nei-Mongo under westerly wind at both the surface and $1.5 \mathrm{~km}$ height and then followed northerly and northwesterly toward the Chinese eastern coast and the Yellow Sea, further moving toward the northern Korea and Gangeung city.

In Figure 7(a), backward trajectories of dust particles generated in Gobi Desert at 09:00 LST (00:00 UTC) on October $25 \mathrm{flew}$ from about $3 \mathrm{~km}$ height of the desert toward Gangneung city in the Korean east coast and reached $1000 \mathrm{~m}$ and $2000 \mathrm{~m}$ levels of the city at 09:00 LST (00:00 UTC), October 27 after three days. The dusts passed by about $2 \sim 3 \mathrm{~km}$ heights of Nei-Mongo in the northern China could reach the city at $1000 \mathrm{~m}$ and $500 \mathrm{~m}$ heights. Thus, dusts transported from Nei-Mongo could directly make a contribution to the increase of PM concentrations in the city as shown in Figure 2. At 21:00 LST (4 hours after the occurrence of maximum PM concentration), a high pressure system of
$1025 \mathrm{hPa}$ was located in the eastern Mongolia and a low pressure system of $1006 \mathrm{hPa}$ was in the northeastern China (Figure 5(b)).

As the previous high and low pressure systems moved toward the east, cold front passed by the northern part of Korean peninsula and stretched toward Manchuria in the north-eastern China. This kind of pressure pattern over Mongolia, China, and Korea caused northerly wind near Gobi Desert and southwesterly wind in the southern China (Figures 6(b) and 6(d)). Southwesterly wind still prevailed through the Korean peninsula including the study area. Thus, dusts generated from Gobi Desert might pass by the eastern Mongolia-Nei-Mongo-southeastern China and finally reached the Korean eastern coastal city, sequentially. As a result, dusts transported from both Gobi Desert and NeiMongo could make a great contribution to the increase of local PM concentration in the city.

In Figure 7(b), as dust particles passed by $3 \mathrm{~km}$ height of Gobi Desert and $2000 \mathrm{~m}$ height of Nei-Mongo flew toward the Korean east coast and reached $2000 \sim 500 \mathrm{~m}$ heights in the city at 17:00 LST, October 27, when a maximum PM concentration took place. Thus, huge amounts of dusts generated from both Gobi Desert and Nei-Mongo could be transported to the city and made a great contribution to the increases of $\mathrm{PM}_{10}, \mathrm{PM}_{2.5}$, and $\mathrm{PM}_{1}$ concentration near the ground surface of the city. Similar patterns of backward particle trajectories could continuously exist until 03:00 LST, October 28 (Figure 7(c)). After 03:00 LST until 09:00 LST, October 28, dust transportation from Gobi Desert toward the Korean coastal city was very difficult as shown in Figure $7(d)$. Even though some amounts of dusts from not Gobi Desert, but Nei-Mongo (outside a box in the figure), passed by the southern China and the Yellow Sea and finally reached the Korean eastern coast, the transported dusts should be not much and local PM concentrations could be under little influence of the dusts.

4.3. Effect of Synoptic-Scale Geopotential Tendency Corresponding to Vorticity on High PM Concentration. Vorticity equation can be derived using horizontal momentum equations. It can be obtained by differentiating the $x$ component equation of momentum with respect to $y$ and the $y$ component equation with respect to $x$ and then subtraction of former differential equation from later differential equation $\zeta=\partial v / \partial x-\partial u / \partial y[27]$.

Vorticity equation has a great advantage in order to investigate upward or downward of motion of air. Downward motion of air occurs in positive vorticity area at $500 \mathrm{hPa}$ level (approximately $5.5 \mathrm{~km}$ height) and oppositely upward motion in negative vorticity area. Opposite to the $500 \mathrm{hPa}$ level, downward motion of air near the ground surface (approximately $1,000 \mathrm{hPa}$ level) occurs in negative vorticity area and vice versa. Holton [27], Sanders and Gyakum [29], and Reed and Albright [30] explained that the region of positive relative vorticity $\left(\zeta ; \times 10^{-5} \mathrm{sec}^{-1}\right)$ at the $500 \mathrm{hPa}$ level causing convergence of air parcel and sequentially its downward motion toward the ground surface matches the region of the negative geopotential tendency $\left(-\partial \Phi / \partial t ; \mathrm{m} \mathrm{day}^{-1}\right)$ at the $500 \mathrm{hPa}$ level. Atmospheric depth in the negative 


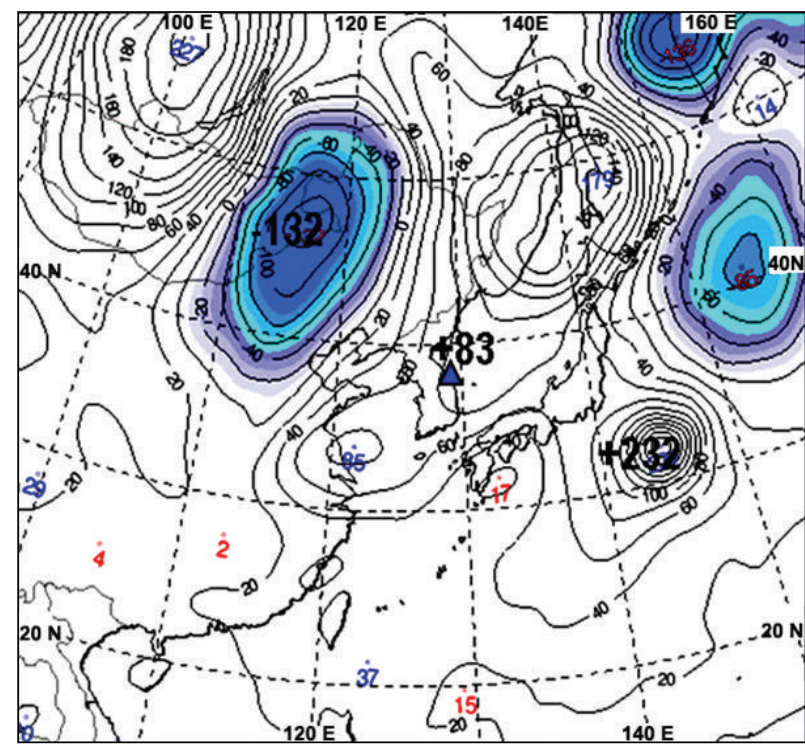

(a)

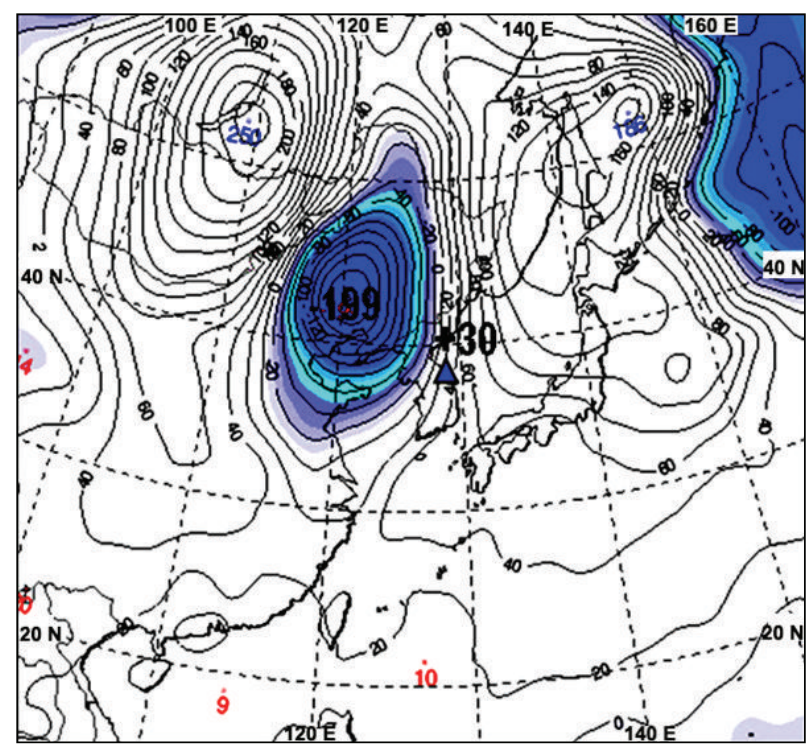

(b)

Figure 9: Geopotential tendency $\left(\partial \Phi / \partial t ; \mathrm{m} \mathrm{day}^{-1}\right)$ at $500 \mathrm{hPa}$ level at (a) 09:00 LST October 27, 2003, and (b) 21:00 LST. Triangle indicates Gangneung city. Shadow (white) area indicates negative (positive) geopotential tendency, which implies the shrunken (expansion) rate of geopotential height change at $500 \mathrm{hPa}$ level for a day. As a positive tendency at 09:00 LST (21:00 LST) in Gangneung city was $+83 \mathrm{~m} \mathrm{day}{ }^{-1}$ $\left(+30 \mathrm{~m} \mathrm{day}^{-1}\right)$, the net one of $-53 \mathrm{~m}$ for 12 hours implies a $53 \mathrm{~m}$-shrunken atmospheric depth at 21:00 LST, causing a maximum PM 10 at 17:00 LST.

geopotential tendency area should be reduced and vertically shrunken (Figure 8). On the other hand, the region of negative relative vorticity $(-\zeta)$ inducing divergence of air parcel at the $500 \mathrm{hPa}$ level and its upward motion from the ground surface toward the $500 \mathrm{hPa}$ level matches the region of the positive geopotential tendency, $\left(+\partial \Phi / \partial t ; \mathrm{m} \mathrm{day}^{-1}\right)$ with vertical expansion of atmospheric depth of $500 \mathrm{hPa}$ level.

For applying geopotential tendency theory, we used every 6-hour weather maps of geopotential height at $500 \mathrm{hPa}$ level supplied by Korea Meteorological Administration (KMA). At 09:00 LST, October 27, when huge amounts of dusts from Gobi Desert and Nei-Mongo began to make a contribution to the increase of PM concentrations at Gangneung city, geopotential tendency at $500 \mathrm{hPa}$ level for a day in the city was $+80 \mathrm{~m} \mathrm{day}^{-1}$ (Figure 9(a)). The positive value of $+83 \mathrm{~m} \mathrm{day}^{-1}$ implies that atmospheric depth of $500 \mathrm{hPa}$ level to the ground surface should be vertically expanded to more $83 \mathrm{~m} \mathrm{day}^{-1}$ than one day before. On the other hand, the tendency at 21:00 LST was changed into $+30 \mathrm{~m} \mathrm{day}^{-1}$, which implied still the expansion of $500 \mathrm{hPa}$ level to be up to $30 \mathrm{~m} \mathrm{day}^{-1}$ for 24 hours (Figure 9(b)). Thus, the net variation of geopotential tendency between 09:00 LST and 21:00 LST for 12 hours could be reduced to $-53 \mathrm{~m}$, resulting in atmospheric depth to be shrunken. Similarly to the case of 21:00 LST, synoptic-scale shrunken atmospheric layer of $100 \mathrm{~m}$ could force nocturnal surface inversion layer in the city to be further more shrunken at night. Thus, resultantly much more shrunken nocturnal surface inversion layer might cause a maximum $\mathrm{PM}_{10}$ concentration as well as $\mathrm{PM}_{2.5}$ and $\mathrm{PM}_{1}$ in the coastal city at 17:00 LST.
Figures 10(a) and 10(b) indicate vorticity $\left(\times 10^{-5} \mathrm{sec}^{-1}\right)$ at $500 \mathrm{hPa}$ level at 09:00 LST October 27, 2003, and 21:00 LST, respectively. At 0900 LST October 27, Gangneung city was in negative vorticity area at the $500 \mathrm{hPa}$ level, which caused upward motion of air with a magnitude of $-4 \times 10^{-5} \mathrm{sec}^{-1}$ from the ground surface toward the $500 \mathrm{hPa}$ height. At 21:00 LST, the city was still in negative vorticity area at the $500 \mathrm{hPa}$ level, but upward motion of air with negative vorticity of $-4 \times 10^{-5} \mathrm{sec}^{-1}$ became weaker than one by its reduction to negative vorticity of $-2.5 \times 10^{-5} \mathrm{sec}^{-1}$, resulting in the shrunken of atmospheric depth between the $500 \mathrm{hPa}$ level to the ground surface.

4.4. Effects of Atmospheric Boundary Layer on High PM Concentration. As shown in Figure 2, under the intensive intrusion of dusts from Gobi Desert toward the city during the dust period, high $\mathrm{PM}_{10}, \mathrm{PM}_{2.5}$, and $\mathrm{PM}_{1}$ concentrations were detected at 09:00 LST at the beginning time of office hour and 17:00 LST at the ending time of office hour, due to emission of gases and particulate matters from high density-traffic vehicles on the road, similarly to ones in the nondust period. As daytime went on after sunrise, convective boundary layer $(\mathrm{CBL})$ due to thermal convection in the inland basin of the mountain top in the west of the city was much more developed than one at 09:00 LST, up to about $500 \mathrm{~m}$ in Figure 11(a), similarly to ones on October 26 (non-Yellow Dust Event period). Under the similar driving mechanism, thermal internal boundary layer (TIBL) during the day was also developed along the eastern slope of the mountain from the coast of the study area to the top of the mountain with about $300 \mathrm{~m}$ thickness. 


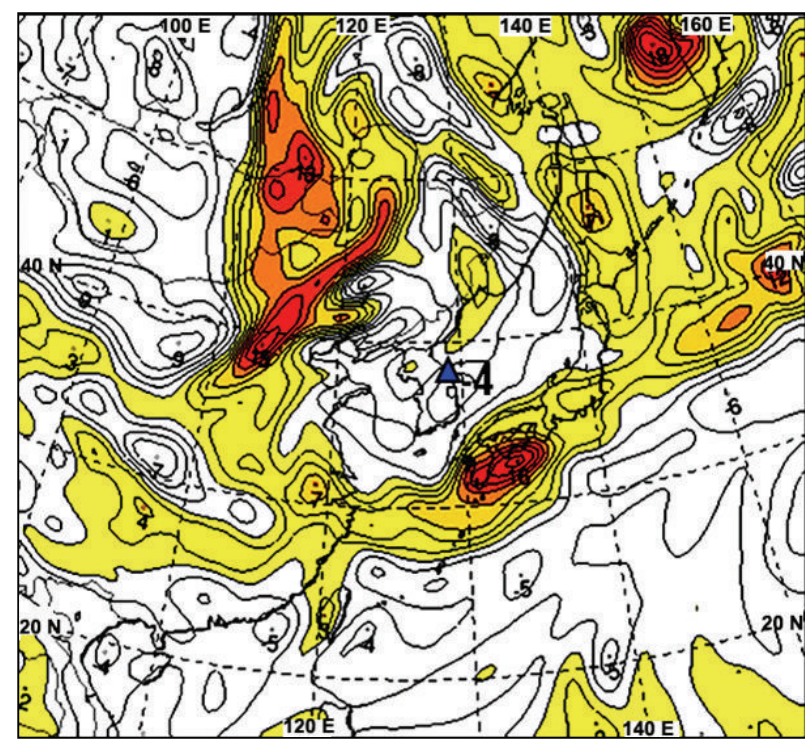

(a)

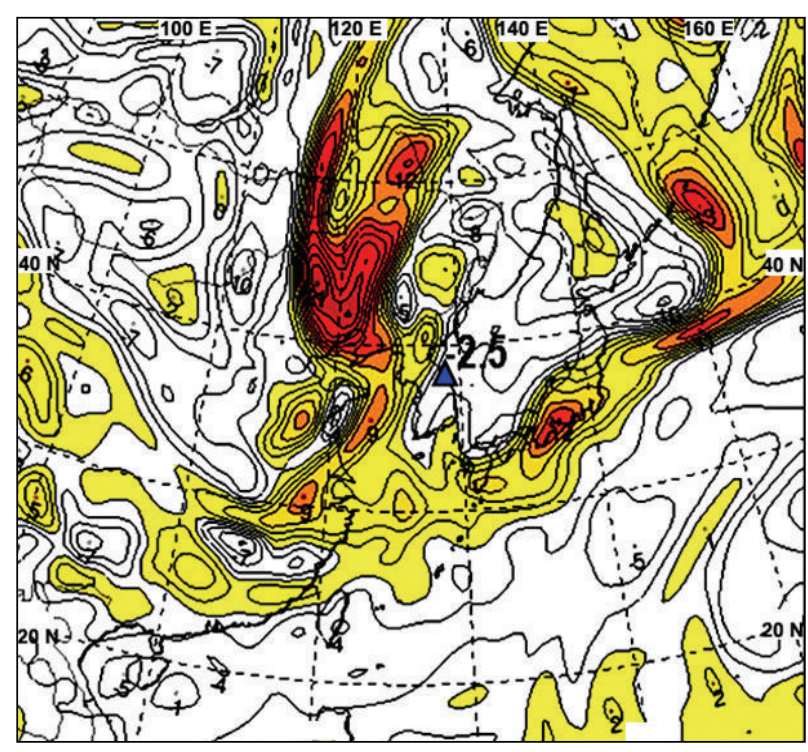

(b)

FIGURE 10: Variations of vorticities $\left(\zeta=\partial v / \partial x-\partial u / \partial y ; \times 10^{-5} \mathrm{sec}^{-1}\right)$ at $500 \mathrm{hPa}$ level at (a) 09:00 LST October 27, 2003, and (b) 21:00 LST. Triangle in the center indicates Gangneung city. Colorful (white) area indicates positive (negative) vorticity, which implies the downward (upward) motion of air at the $500 \mathrm{hPa}$ level and corresponds to negative (positive) geopotential tendency area. Upward motion of air at the $500 \mathrm{hPa}$ level with negative vorticity of $-2.5 \times 10^{-5} \mathrm{sec}^{-1}$ at 21:00 LST became weaker than one with negative vorticity of $-4 \times 10^{-5} \mathrm{sec}^{-1}$ at 09:00 LST, resulting in shrunken atmospheric depth.

The maximum developments of CBL and TIBL occur around 12:00 15:00 LST, when maximum thermal convection takes place $[31,32]$. Thus, although particulate matters emitted from vehicles on the road of the coastal city could increase for daytime hours, the particulates emitted from the ground surface of the city were uplifted to the top of the vertically developed TIBL and PM concentrations near the ground surface were generally very low on October 26 in the Gangneung coast. However, as the PM concentrations at Gangneung city continuously increased on October 27, due to huge amounts of dusts transported from Gobi Desert and Nei-Mongo toward the city, their concentrations with their still increasing trends were slightly lower at both 12:00 LST and 15:00 LST than 09:00 LST (Figures 2 and 11(a)).

On the other hand, from 16:00 LST, October 27 until 04:00 LST, October 28, as huge amounts of dusts transported from Gobi Desert and Nei-Mongo toward Gangneung city under northerly wind (China), southwesterly wind (Yellow Sea) and southwesterly wind (Korean peninsula) increased rapidly and also combined with the dust and gases emitted from the ground surface of Gangneung city, local $\mathrm{PM}_{10}$ concentration continuously increased to a maximum value of $154.57 \mu \mathrm{g} \mathrm{m}^{-3}$ at 17:00 LST, October 27, which was $84.7 \mu \mathrm{g} \mathrm{m}^{-3}$ larger than a maximum one of $69.87 \mu \mathrm{g} \mathrm{m}^{-3}$ at 18:00 LST, October 26 (nonYellow Sand Event period). Similarly, maximum value of $\mathrm{PM}_{2.5}\left(\mathrm{PM}_{1}\right)$ also reached $93.19 \mu \mathrm{g} \mathrm{m}^{-3}\left(76.05 \mu \mathrm{g} \mathrm{m}^{-3}\right)$, which was much larger than ones of $27.19 \mu \mathrm{g} \mathrm{m}^{-3}\left(20.21 \mu \mathrm{g} \mathrm{m}^{-3}\right)$, respectively.

Particularly, shortly after sunset around 17:00 LST in Korea, nocturnal cooling of the ground surface causes cooling of air masses near ground surface and produces nocturnal surface inversion layer (NSIL), which is much more shrunken than the daytime thermal internal boundary layer (Figure 11(b)). Both dusts transported from Gobi Desert toward Gangneung city should combine with ones from vehicles on the road and heating boilers from resident area of Gangneung city. The combined dusts were trapped under much shallower and shrunken NSIL of about 50 100 $\mathrm{m}$ depth, resulting in the increase of PM concentrations with their maximum values around 17:00 LST.

In the previous research by Choi and Choi [20], nocturnal surface inversion layer in the coastal basin of Gangneung city was developed to 200 250 $\mathrm{m}$ height over the ground surface in March. Differently from their researches, in our case, synoptic-scale shrunken atmospheric depth from $500 \mathrm{hPa}$ level to the ground surface due to the reduction of geopotential tendency for 12 hours $(-53 \mathrm{~m})$ could directly cause the decrease of nocturnal surface inversion layer depth. Thus, nocturnal surface inversion layer at 17:00 LST, October 27, could be about 150 200 $\mathrm{m}$ shallower than usual daytime thermal internal boundary layer. Thus, the shallower NSIL might make more contribution to the occurrence of a maximum PM concentration at 17:00 LST.

Reed and Sanders [33] explained theoretically that potential vorticity can be used as a tracer like air parcel or dust. Haynes and McIntrye [34] showed that potential vorticity can be diluted or concentrated only by flow across isentropes and it cannot be created or destroyed within a layer bounded by isentropic surfaces. Thus, Choi and Zhang [9] described in detail the dust transportation route, using relative vorticity and depicting shade area in Figure 11(b) with the big magnitudes of potential vorticity near the ground surface 


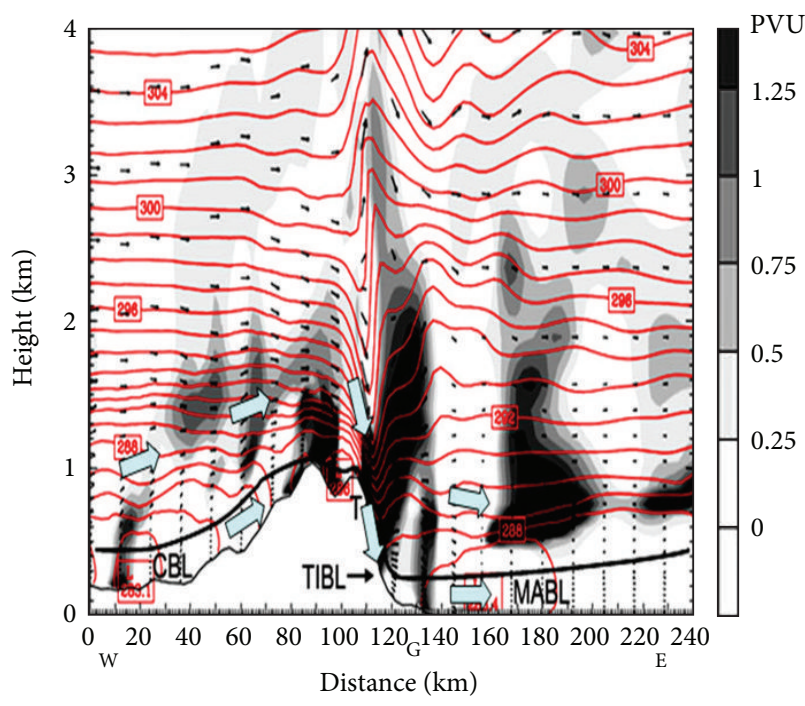

(a)

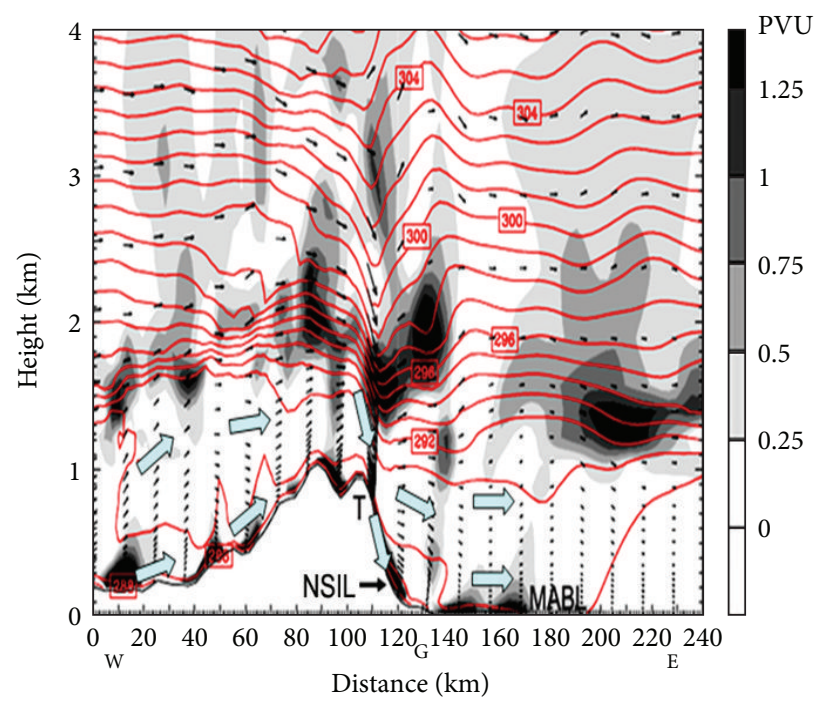

(b)

FIGURE 11: (a) Vertical profiles of potential temperature (k), wind speed $(\mathrm{m} / \mathrm{s})$, and potential vorticity $\left(\mathrm{PVU}=10^{-6} \mathrm{~m}^{2} \mathrm{~s}^{-1} \mathrm{k} \mathrm{kg}^{-1}\right)$ on a horizontal cutting line in the third domain of WRF model simulation in Figure 6 at (a) 09:00 LST and (b) 17:00 LST, October 27, 2003. Thick line, CBL, TIBL, G, and MABL on the bottom in (a) and (b) denote the top of convective boundary layer, thermal internal boundary layer, Gangneung city, and marine atmospheric boundary layer, respectively. Shade area near the surface in (b) is nocturnal surface inversion layer (NSIL) much shallower than TIBL in (a), where the dusts transported from the northern China combining with the dust particles floated from Gangneung city were merged into the ground surface, resulting in high PM concentrations at 17:00 LST at the city, similar to $[9,20,31,32]$.

of downwind side area and the shade area implied the accumulation of air masses inside a strong stable atmospheric layer. Thus, in Figures 11(a) and 11(b), the shade area with dense isotherm near the ground surface of the mountain and coast at 17:00 LST, October 27, denotes the merge of dust particles inside the NSIL, showing a maximum PM concentration in Figure 2.

\section{Conclusions}

Huge transportation of dusts was detected from Gobi Desert and Nei-Mongo in the northern China toward the Korean coastal city from 09:00 LST, October 27, to 05:00 LST, October 28, using the analysis of backward trajectories by HYSPLIT model and simulated surface wind by WRF model, and local concentrations of PM during Yellow Sand period were more than three times higher than ones before or after the event period. Under the combination of dusts transported from China, high PM concentrations occurred at 09:00 LST (beginning time of office) due to particulate and gases locally emitted from vehicles of a high traffic density on the road in the city, and maintaining their increasing trends with time for daytime hours, maximum ones were detected at 17:00 LST (ending time of office), additionally with the operation of heating boilers from the resident area near sunset, showing abrupt higher PM concentrations.

The reduction of geopotential tendency of $500 \mathrm{hPa}$ level for 12 hours corresponding to positive vorticity caused vertically shrunken synoptic-scale atmospheric depth, which could force nocturnal surface inversion layer to be further shrunken with at least $200 \mathrm{~m}$ shortly around sunset. The combined dusts from Gobi Desert with ones emitted from the Gangneung city should be merged into the ground surface and trapped within much shrunken stable surface inversion layer, resulting in a maximum $\mathrm{PM}_{10}$ concentration as well as $\mathrm{PM}_{2.5}$ and $\mathrm{PM}_{1}$ in the city at 17:00 LST.

\section{Conflict of Interests}

The authors declare that there is no conflict of interests regarding the publication of this paper.

\section{Acknowledgments}

This work was funded by the Korea Meteorological Administration Research and Development Program under Grant CATER 2006-2308 "Generation mechanism and prediction of wind storm in the mountainous coast" in 2011 2012 research year. This paper includes a partial fulfillment of Ph.D. dissertation of Dr. Mi Sook Lee in 2012.

\section{References}

[1] X. Zhang, R. Arimoto, Z. An et al., "Atmospheric trace elements over source regions for Chinese dust: concentrations, sources and atmospheric deposition on the Loess Plateau," Atmospheric Environment A, vol. 27, no. 13, pp. 2051-2067, 1993.

[2] Y. Chung and M. Yoon, "On the occurrence of yellow sand and atmospheric loadings," Atmospheric Environment, vol. 30, no. 13, pp. 2387-2397, 1996. 
[3] Y. S. Chung, H. S. Kim, L. Natsagdorj, D. Jugder, and S. J. Chen, "On yellow sand occurred during 1997-2000," Journal of Korean Meteorological Sciences, vol. 37, pp. 305-316, 2001.

[4] H. Choi, "Comparison of $\mathrm{PM}_{1}, \mathrm{PM}_{2.5}$ and $\mathrm{PM}_{10}$ concentrations in a mountainous coastal city, Gangneung before and after the Yellow Dust event in spring," Journal of the Environmental Sciences, vol. 17, no. 6, pp. 633-645, 2008.

[5] H. Choi, "Impact of fine particulate matters transported from Gobi Desert to particulate concentrations $\left(\mathrm{PM}_{10}, \mathrm{PM}_{2.5}, \mathrm{PM}_{1}\right)$ for Yellow Sand Event period in Fall-Case study of October 27, 2003," Journal of Climate Research, vol. 5, no. 3, pp. 219-233, 2010.

[6] H. Choi, "Characteristics of hourly variation of gaseous pollutant concentration at Gangneung, Korea for Yellow Sand Event period in winter-case study of February 14-16, 2005," Journal of Climate Research, vol. 6, no. 1, pp. 59-76, 2011.

[7] X. Wang, Y. Ma, H. Chen et al., "The relation between sandstorms and strong winds in Xinjiang, China," Water, Air, and Soil Pollution, vol. 3, no. 2, pp. 67-79, 2003.

[8] Y. Zhang and Y. Zhong, "The simulation and diagnosis for a strong wind associated with northeast low," Acta Meteorolgical Sinica, vol. 43, pp. 97-105, 1985.

[9] H. Choi and Y. H. Zhang, "Predicting duststorm evolution with the vorticity theory," Atmospheric Research, vol. 89, no. 4, pp. 338-350, 2008.

[10] I. Tegen and I. Fung, "Modeling of mineral dust in the atmosphere: sources, transport, and optical thickness," Journal of Geophysical Research D, vol. 99, no. 11, pp. 22987-22914, 1994.

[11] V. R. Kotamarthi and G. R. Carmichael, "The long range transport of pollutants in the Pacific Rim region," Atmospheric Environment A, vol. 24, no. 6, pp. 1521-1534, 1990.

[12] G. R. Carmichael, M. Hong, H. Ueda et al., "Aerosol composition at Cheju Island, Korea," Journal of Geophysical Research D, vol. 102, no. 5, pp. 6047-6061, 1997.

[13] I. G. McKendry, J. P. Hacker, R. Stull, S. Sakiyama, D. Mignacca, and K. Reid, "Long-range transport of Asian dust to the Lower Fraser Valley, British Columbia, Canada," Journal of Geophysical Research D, vol. 106, no. 16, pp. 18361-18370, 2001.

[14] T. Lin, "Long-range transport of yellow sand to Taiwan in Spring 2000: observed evidence and simulation," Atmospheric Environment, vol. 35, no. 34, pp. 5873-5882, 2001.

[15] M. T. David, J. F. Robert, and L. W. Douglas, "April 1998 Asian dust event: a southern California perspective," Journal of Geophysical Research D, vol. 106, no. 16, pp. 18371-18379, 2001.

[16] K. Kim, G. Choi, C. Kang et al., "The chemical composition of fine and coarse particles in relation with the Asian Dust events," Atmospheric Environment, vol. 37, no. 6, pp. 753-765, 2003.

[17] M. S. Lee and J. D. Chung, "Impact of yellow dust transport from Gobi Desert on fractional ratio and correlations of temporal $\mathrm{PM}_{10}, \mathrm{PM}_{2.5}$ and $\mathrm{PM}_{1}$ at Gangneung city in fall," Journal of the Environmental Sciences, vol. 21, no. 2, pp. 217-231, 2012.

[18] I. Tegen and R. Miller, "A general circulation model study on the interannual variability of soil dust aerosol," Journal of Geophysical Research D, vol. 103, no. 20, pp. 25975-25995, 1998.

[19] H. Choi and M. S. Speer, "Effects of atmospheric circulation and boundary layer structure on the dispersion of suspended particulates in the Seoul metropolitan area," Meteorology and Atmospheric Physics, vol. 92, no. 3-4, pp. 239-254, 2006.

[20] H. Choi and D. S. Choi, "Concentrations of $\mathrm{PM}_{10}, \mathrm{PM}_{2.5}$, and $\mathrm{PM}_{1}$ influenced by atmospheric circulation and atmospheric boundary layer in the Korean mountainous coast during a duststorm," Atmospheric Research, vol. 89, no. 4, pp. 330-337, 2008.

[21] H. Choi, Y. H. Zhang, and K. H. Kim, "Sudden high concentration of TSP affected by atmospheric boundary layer in Seoul metropolitan area during duststorm period," Environment International, vol. 34, no. 5, pp. 635-647, 2008.

[22] H. Choi, D. S. Choi, and S. M. Choi, "Meteorological condition and atmospheric boundary layer influenced upon temporal concentrations of $\mathrm{PM}_{1}, \mathrm{PM}_{2.5}$ at a Coastal City, Korea for Yellow Sand Event from Gobi Desert," Disaster Advances, vol. 3, no. 4, pp. 309-315, 2010.

[23] H. Choi, "Trapping effect of a calm zone by lee side-internal gravity waves and cyclonic winds on sudden high concentrations of particulate matters combined with the Yellow Dusts from Gobi Desert in the Korean eastern coast," Disaster Advances, vol. 6, no. 11, pp. 101-111, 2013.

[24] L. Uzan and P. Alpert, "The coastal boundary layer and air pollution-a high temporal resolution analysis in the East Mediterranean coast," The Open Atmospheric Science Journal, vol. 6, pp. 9-18, 2012.

[25] H. Choi and M. S. Lee, "Atmospheric boundary layer influenced upon hourly $\mathrm{PM}_{10}, \mathrm{PM}_{2.5}, \mathrm{PM}_{1}$ concentrations and their correlations at Gabgbeubg city before and after Yellow Dust transportation from Gobi Desert," Journal of Climate Research, vol. 7, no. 1, pp. 30-54, 2012.

[26] KMA, Korean Meteorological Administration, 2003.

[27] J. R. Holton, An Introduction to Dynamic Meteorology, Academic Press, 4th edition, 2004.

[28] H. Choi, M. S. Lee, and S. M. Choi, "Cold sea surface temperature near Cheju Island responding to strong cyclonic wind and positive geopotential tendency behind a typhoon center along its track," Journal of Marine Science and Technolgy, vol. 20, no. 6, pp. 684-692, 2012.

[29] F. Sanders and J. R. Gyakum, "Synoptic-dynamic climatology of the "bomb" ( extratropical surface cyclone)," Monthly Weather Review, vol. 108, no. 10, pp. 1589-1606, 1980.

[30] R. J. Reed and M. D. Albright, "A case study of explosive cyclogenesis in the eastern Pacific," Monthly Weather Review, vol. 114, no. 12, pp. 2297-2319, 1986.

[31] H. Choi and S. M. Choi, "Generation of windstorm in the eastern mountainous coast of Korea," Disaster Advances, vol. 3, no. 2, pp. 24-34, 2010.

[32] H. Choi, Y. H. Zhang, and S. Takahashi, "Recycling of suspended particulates by the interaction of sea-land breeze circulation and complex coastal terrain," Meteorology and Atmospheric Physics, vol. 87, pp. 109-120, 2004.

[33] R. J. Reed and F. Sanders, "Investigation of the development of a mid-tropospheric frontal zone and its associated vorticity field," Journal of Meteorology, vol. 10, pp. 338-349, 1953.

[34] P. H. Haynes and M. E. McIntrye, "On the evolution of vorticity and potential vorticity in the presence of diabatic heating and frictional or other s forces," Journal of Atmospheric Sciences, vol. 44, pp. 828-841, 1987. 

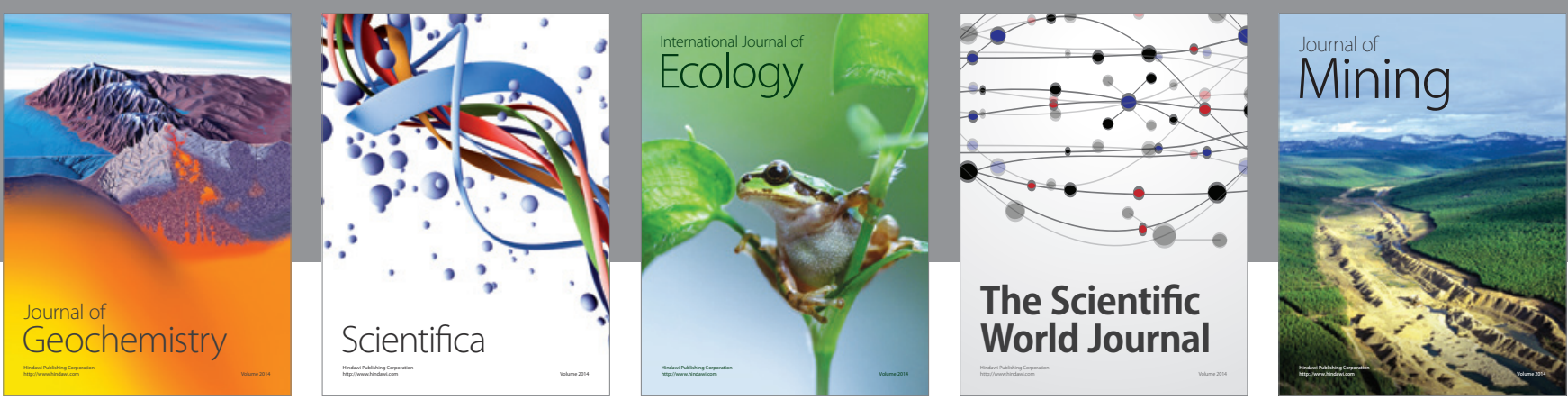

The Scientific World Journal
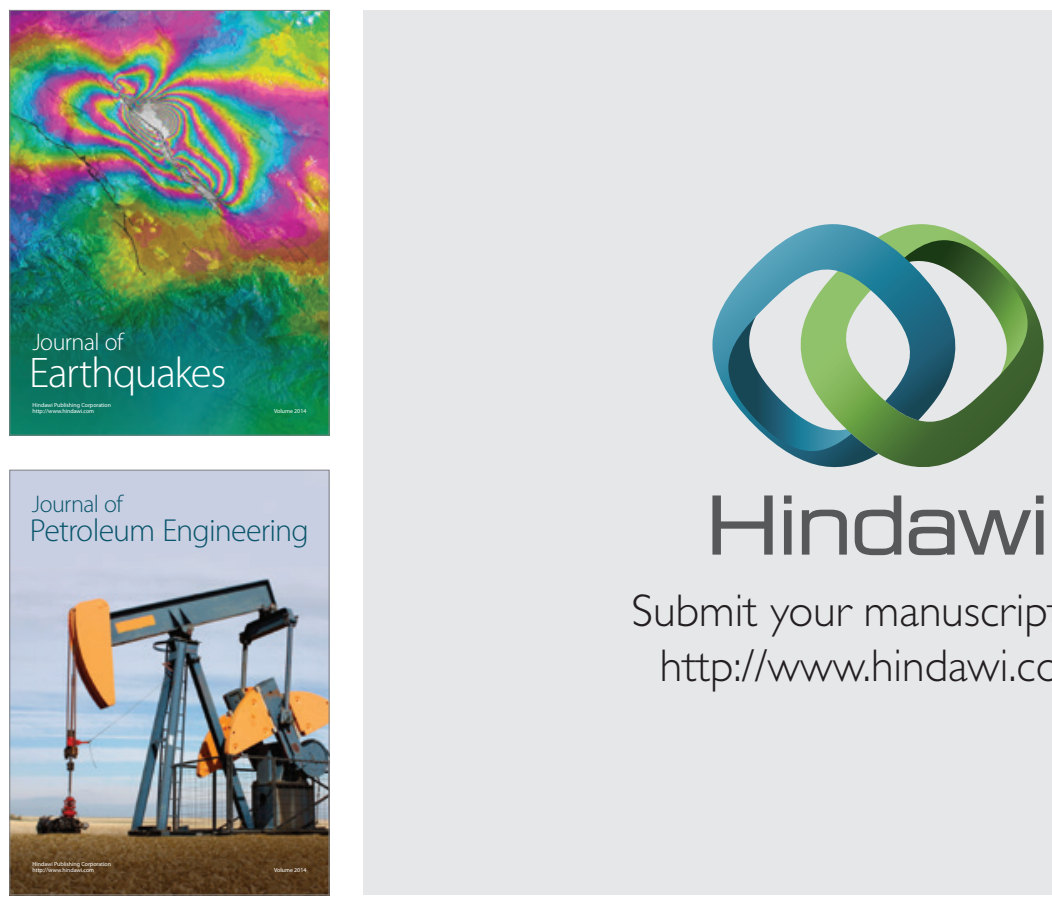

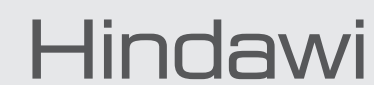

Submit your manuscripts at

http://www.hindawi.com
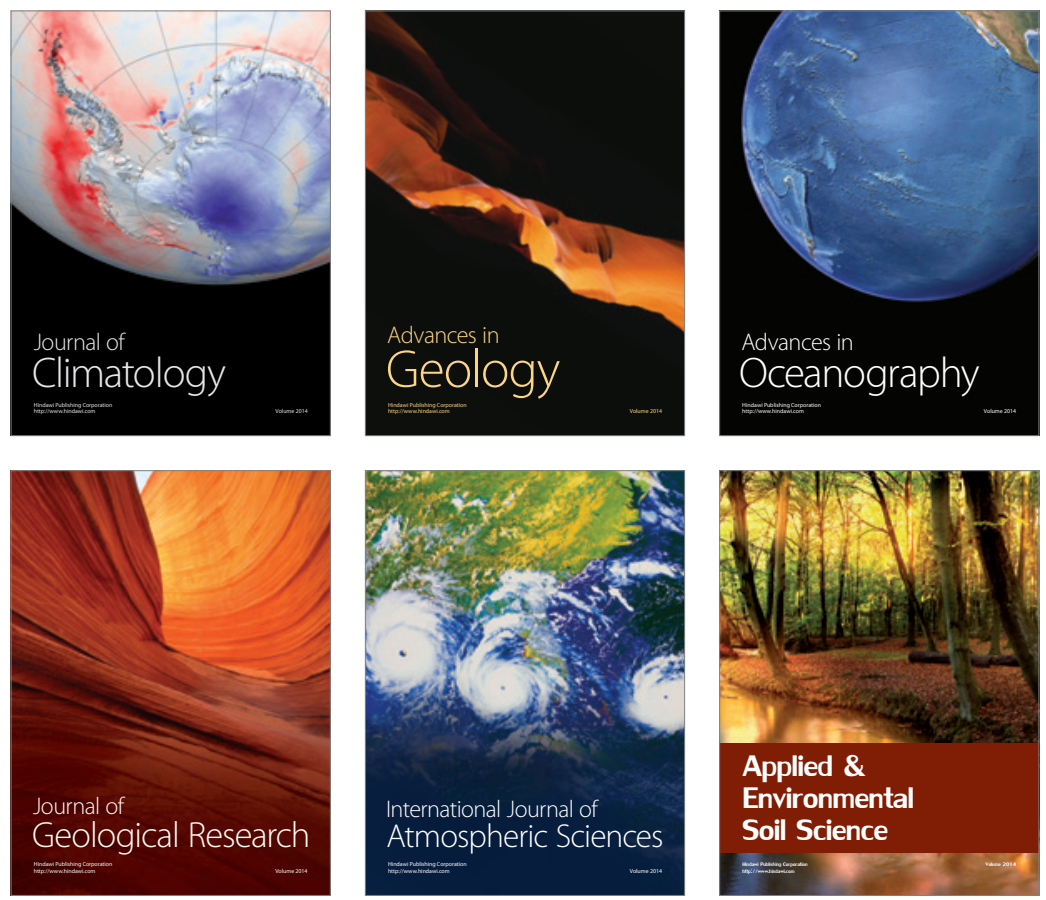
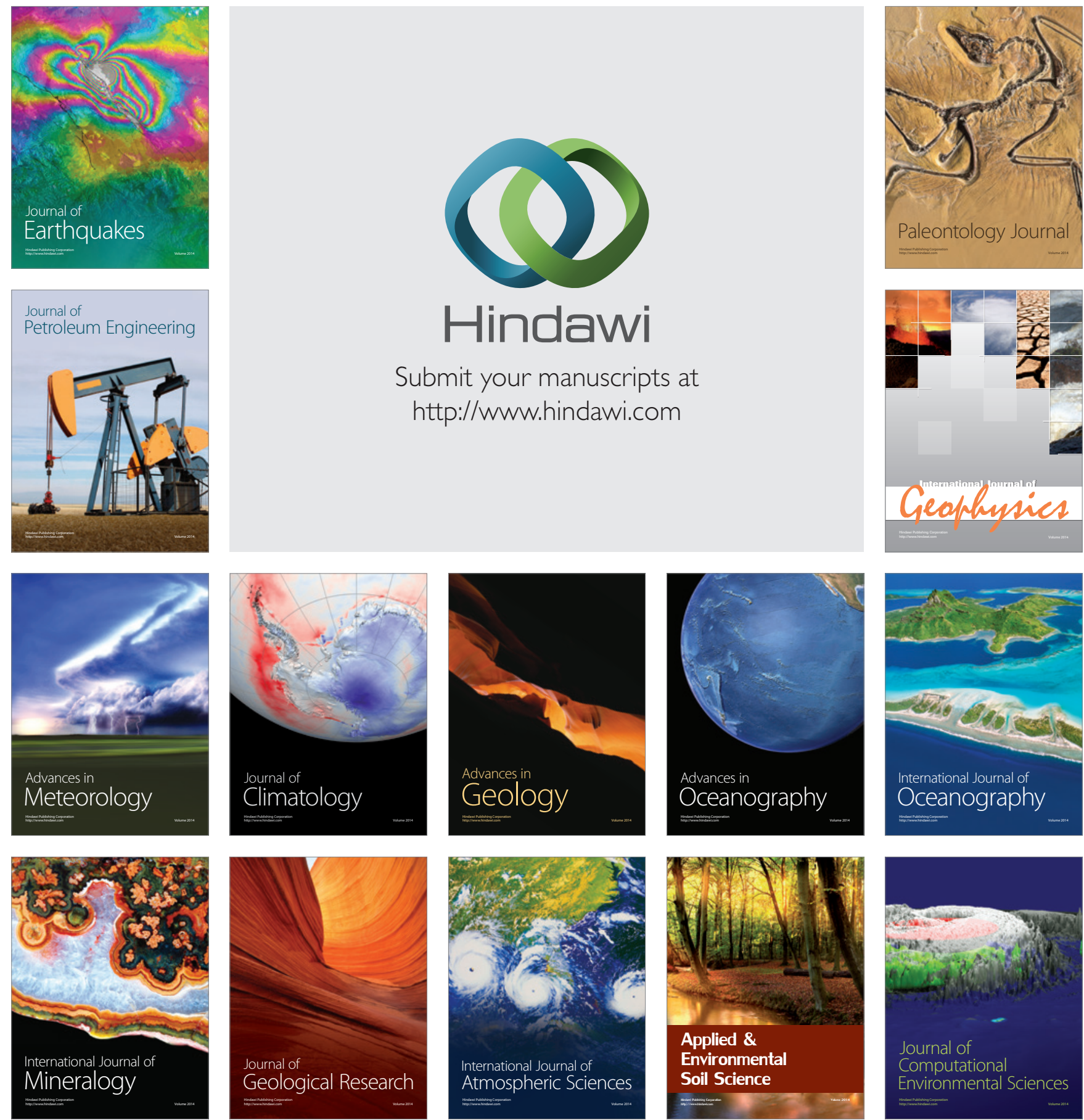